\title{
FE Modeling and Numerical Investigation of Shallow Cellular Composite Floor Beams
}

\author{
Toi Limazie, Shiming Chen* \\ School of Civil Engineering, Tongji University, Shanghai 200092, China \\ *Corresponding author: Tel.: +8621 65986183; fax: +862165982668 \\ E-mail address: chensm@tongji.edu.cn
}

\begin{abstract}
The behavior of shallow cellular composite floor beam is normally governed by the shear transfer mechanism at the contact interface between the concrete slab and the encased steel beam, thus by the influence of the two materials. A detailed finite element modeling approach in investigating the structural behavior of shallow cellular composite floor beam is presented. The shear bound at the contact interface between the concrete slab and the steel beam is simulated by using the contact modeling and considering the adhesion, the friction and the local compression at all the contact zones. Both the material and geometric nonlinearities are considered in the FE modeling of the shallow cellular composite beams. The FEA results are calibrated and validated against the test results and the comparisons indicated that the FE analysis procedures with the contact modeling agree well with the test results, and can accurately predict the flexural behavior and the load bearing capacity of the composite slim floor beam. An extensive parametric study is further conducted to investigate all
\end{abstract}


the likely influences of the parameters such as geometric dimensions and the web openings size and spacing on the structural performance of the shallow cellular composite floor beam.

Keywords: Finite element modeling; shear transfer; shallow cellular composite beam; contact modeling; tie-bar element; web opening.

\section{Introduction}

Shallow Cellular Composite Floor beam (SCCFB) is a new type of composite floor beam which is usually composed of the deep steel decking, the concrete slab and an encased steel beam with regularly spaced opening performed within the web post, resulting in a flat appearance (Fig. 1). It offers important benefits in terms of cost such as the construction flexibility and speed, long spanning capabilities without or with fewer secondary beams, shallow floor depth, inherent fire resistance, etc [1-3]; [4], as well as others advantages offered by ordinary composite beam construction. Due to its merits, composite slim floor systems have been successfully used in many modern building projects such as commercial and residential buildings, hospitals, schools, etc. However, compared to other conventional steel and concrete composite constructions, application of the composite slim floor has been limited in many countries due to the lack of design specifications and practical analysis procedures.

The structural performance of a shallow cellular composite floor beam is governed by the shear transfer mechanism within the composite beam as well as by the performance of the concrete slab and the structural steel beam. To achieve the desired composite action and the desired load bearing capacity, the longitudinal shear forces within the composite beam has to be effectively transferred between the 
concrete slab and the steel beam. For an ordinary composite slim floor beam, the transfer of the longitudinal shear forces is achieved through the mechanical interlock mechanism, while for the shallow cellular composite floor beam (SCCFB) the shear transferring is achieved by the shear bound at the contact interfaces and the shear connection systems which consist of the cast-in-place concrete passing through the steel web opening combined with an embedded reinforcing bar. Besides, the structural behavior and desired composite action of a composite slim floor beam would be also influenced by the geometric and material characteristics of both the concrete slab and the steel beam.

Experimental investigations on integrated slim floor beams have been conducted in Helsinki University of Technology; and the influences of the parameters such as reinforcement ratios and types of loading on the behavior of composite slim floor beams were investigated by Bernuzzi et al. [5]. Mullett et al. [6] also conducted tests on slim floor beams using the hollow core precast units and proposed a design guidance for Slimflor beams. The design guidance was in accordance with the BS5950: Part 1: 1990 [7]. Slimflor beams using the profiled deep decking were also investigated by Mullett and Lawson [8] and some design tables and worked examples were given. A full-scale slim-floor beam test was presented by Mullett, where the shear transfer between the steel section and the concrete slab was provided by the shear bond at the interface between the concrete slab and the steel beam. Wang [10] presented an experimental study of slimfloor beams using deep decking with fixed end connection to a column frame. Also, four full-scale tests were carried out on two span continuous composite floor systems $(6 \mathrm{~m} \times 10 \mathrm{~m})$ by Hegger et al., [11]. However, the structural mechanism of this integrated composite slim floor beam system has not yet been well understood. Investigating the longitudinal shear force as 
well as the influence of the geometric and material characteristics on the structural behavior of composite slim floor beams would require cumbersome experimental investigations that would result to expensive testing programs. Also, due to the semiempirical nature of the experimental investigations, it would be difficult to obtain a clear picture of the physical behavior at the concrete interface between the concrete slab and the steel beam, as within the shear connection system.

During the last decade, attempts have been made to develop design and analysis procedures consisting of computer-based methods which can be used for the analysis of the composite beams, instead of the standard large-scale testing programs, aiming to move away from expensive experimental tests but taking into account all the parameters that could be ignored in the physical tests.

Numerical analytical and FE analyses are alternative methods in investigating the complex structural behavior of composite slim floor beam. Based on the principle of virtual work, Ranzi et al. [12-14] proposed an analytical formulation to analyze the generic multi-layered composite beams which were composed by $n$ layers and interconnected by flexible interface connections between the adjacent layers. A multi-layer laminated composite structure model was also proposed by Karama [15] to predict the mechanical behavior of the multi-layered laminated composite structures. Uy and Bradford [16] proposed a straightforward method to predict the moment-curvature relation of profiled composite beams using the nonlinear stress-strain relation of materials. Several others methods were also reported to investigate the moment-curvature behavior of a multi-layered composite beam. However, most of these methods would require cumbersome numerical calculations to ensure a convergence in the solution. Recently, Limazie and Chen [17] proposed a simple design method to predict the nonlinear behavior of a composite 
slim floor beam considering the effect of the composite action available within the composite beam system.

Compared with an experimental investigation, the FE analysis has the advantages of lower time consumption with lower cost and higher efficiency. The accuracy and reliability of the FE analysis have been demonstrated by many researchers in the past. For composite floors with shear bond interaction, various FE models have been proposed. Daniels and Crisinel [18] developed a FE procedure using the plane beam elements to analyzed single and continuous span composite slabs, in which the nonlinear behavior of the materials was well considered. Veljkovic [19] performed 3D FE analysis using software DIANA to investigate the behavior of steel concrete composite slabs, where the shear bond between the steel deck and the concrete was modeled using a nodal interface element. Abdullah and Easterling [20] also developed a procedure to generate the shear bond property from bending tests. The shear bond property or shear bond-slip curves were then applied to connector elements within the FE models to simulate the horizontal shear in the composite slabs. Widjaja [21] used two parallel Euler-Bernoulli beam elements to simulate the bending test of composite slab, but only one single typical longitudinal slice of the slab was considered in the model, and the vertical nodal displacements of the two parallel beam elements were forced to be the same. Ferrer et al. [22] simulated the pull-out tests of composite slabs using the FE method, in which the contact elements were implemented between the steel deck and the concrete, and various coefficients of friction were analyzed. Tsalkatidis and Avdelas [23] also proposed a model where the shear bond mechanism at the contact interface of the composite slabs was treated as a unilateral contact problem and simplified as a two dimensional contact model. 
In this paper, a FE modeling approach is proposed to investigate the complex structural behavior of SCCFB considering the realistic shear transferring provided by the shear connection system and the shear bond at the contact interface between the concrete slab and steel beam. The shear transfer mechanism is modeled using the contact modeling considering the adhesion, the friction and the local compression at the contact zones between different components of the composite beam. The geometric and material nonlinearities are all considered in the FE modeling. The FE simulation results were calibrated and validated against the bending tests conducted by Chen et al. [24], and it was illustrated that the numerical simulations results agree well with the test results. An extensive parametric study, with the aim of providing design suggestion, was therefore conducted to further investigate all the likely material and geometric parameters influences on the overall performance of a shallow cellular composite beam, such as the load bearing capacity, stiffness and slip capacity.

\section{The shear transferring system in SCCFB}

The shear transferring mechanism in a shallow cellular composite floor beam is assumed to be achieved by the shear bond effect at the contact interface together with the shear connection system which is composed of the cast-in-concrete passing through the web openings and reinforcing bars. This shear connection system as shown in Fig. 2 is able to effectively transfer the longitudinal shear forces between the concrete slab and the steel beam.

The configuration and shear transferring mechanism of this shear connection are quite different from those observed in conventional down-stand composite beams and are very similar but not same as those in the perfobond shear connection. As shown in Fig.2, since the concrete completely fills the web openings, the force flow will occur 
at the steel-concrete interface and in addition to the resistant force of the infill concrete element. The steel element is embedded within the concrete achieving a highest capacity for the shear connection, together with the combination with the infill concrete element and the reinforcing tie-bar element. The force transferring between different components within the SCCFB can likely be interpreted as follows: under flexural loading, the adhesion, the friction and the local compression are all activated at the contact zone of the connection system, and the steel element would be subjected to longitudinal shear causing bending and shear stresses in the steel element. As the load increases, and the shear resistance capacity of concrete is reached, large amount of slip would occur at the contact interface between the steel beam and the concrete slab, with cracks initiation within the infill concrete element. At this stage, the tie-bar element within the infill concrete will lock the concrete and improve the post-failure behavior of the shear connection. As the concrete crushing continues, the tie-bar element will increase the load bearing capacity of the concrete element. As the load continue to increase, cracks will also spread out in the infill concrete as well as in the concrete slab and redistribution of the internal forces occurs in the shear connection. To enable a desired load bearing and ductile performance of the shear connection, the presence of the steel tie-bar element would be critical, so that the infill concrete must be able to carry the resulting tensile forces, without it, the shear connection will exhibit a brittle failure mode.

\section{Finite element models}

The FE analyses presented in this paper are based on the four shallow cellular composite floor beams tested by Chen et al. [24] and the FEA program ANSYS 11.0 was used to develop the FE models. 
The composite beams were composed of $75 \mathrm{~mm}$ depth profiled steel decking, a cellular steel beam with regularly spaced web openings and the cast-in-place concrete slab [24]. All the four composite beam specimens (named as SCCFB $1 \sim$ SCCFB 4) were $4.2 \mathrm{~m}$ length beams spanning over $4.0 \mathrm{~m}$ between the supports and have $1.0 \mathrm{~m}$ concrete slab width. The embedded steel beams consist of an "asymmetric I section steel beam" for SCCFB 1 and SCCFB 2 and an "inverted T section steel beam" for SCCFB 3 and SCCFB 4. Specimens SCCFB 1 and SCCFB 2 have 13 circular openings with $100 \mathrm{~mm}$ diameter and spaced at $305 \mathrm{~mm}$ at their center. While specimens SCCFB 3 and SCCFB 4 have 13 clothoidal openings, also spaced at $305 \mathrm{~mm}$ at the center. The geometrical dimensions of the four specimens are illustrated in Fig. 3(a) and Fig. 3(b).

The specimens in the FE simulation are all simply-supported composite beams subjected to a two-point symmetric loading configuration. The composite beams were composed of the concrete slab and the structural steel beam with regularly spaced openings, while the concrete plug with tie-bar shear connection is composed of concrete cone element with the reinforcing tie-bar element. Due to the symmetry of the specimens, only one half of the specimen was modeled in the FE analysis, with appropriate boundary conditions. Also, in the purpose of saving the computing time and cost of the FE simulations, the solid concrete slab was used rather than the ribbed slab as in tests, since in the configuration of the specimen, the steel decks were placed perpendicular to the axis of the steel beam and would not contribute to the force resisting and nor influence the shear transferring of the composite beam.

\subsection{Element types and model meshing}


The concrete elements were modeled using Solid65, an eight-node and threedimensional solid element, which is capable of modeling crushing of concrete in compression and cracking in tension. Fig. 4(a) shows the schematic illustration of the Solid65 element. The steel beam was modeled using Shell181 as shown in Fig. 4(b), which is a four-node element with six degrees of freedom at each node and wellsuited for large strain non-linear analysis for thin to moderately-thick structures. The reinforcing bars embedded in the concrete slab and the tie-bars used for the shear connections were all modeled using the spar element Link8. This 3D spar element is a uniaxial tension-compression element with three degrees of freedom at each node and has plasticity, creep, swelling, stress stiffening and large deformation capabilities as the Solid65 element.

To achieve accurate and efficient FE models, the build-up models were all meshed with controlled element size. The Shell181 element for the steel beam was meshed in $25 \mathrm{~mm} \times 25 \mathrm{~mm}$ size, but with refined mesh size around the openings in order to accurately simulate the stress concentration phenomenon around the openings. The concrete volume was meshed about $50 \mathrm{~mm} \times 50 \mathrm{~mm}$ in size; while the reinforcing bars were also meshed in a size of $50 \mathrm{~mm}$. The geometric and material nonlinearities were both involved in the FE analysis and therefore appropriate nonlinear materials models were well assigned to each element. An overall view of the typical FE model of the slim beam using "asymmetric I section" steel beam is illustrated in Fig. 5.

\subsection{Material properties modeling}

Material properties of the concrete and steel elements obtained from the concrete compressive strength test and from the tensile coupon tests were adopted and used in the finite element analysis. For the concrete material, the stress and strain were determined in accordance with the Chinese code for concrete design (GB50010-2010) 
[25], using Eqs. (1-1) and (1-2). Accordingly the concrete reaches its maximum compressive stress at the strain value of 0.002 , and beyond the peak stress $\left(f_{c}\right)$, the concrete strain would reach the maximum value of 0.0033 .

For $\varepsilon_{\mathrm{c}} \leq \varepsilon_{0}$ :

$$
\sigma_{c}=f_{c}\left[1-\left(1-\frac{\varepsilon_{c}}{\varepsilon_{0}}\right)^{n}\right]
$$

For $\varepsilon_{0}<\varepsilon_{\mathrm{c}} \leq \varepsilon_{\mathrm{cu}}$ :

$$
\sigma_{c}=f_{c}\left[1-0.15\left(\frac{\varepsilon_{c}-\varepsilon_{0}}{\varepsilon_{c u}-\varepsilon_{0}}\right)\right]
$$

The strain-stress curve under the uniaxial compression was associated to the failure criteria and strengthening criteria to define the multi-linear isotropic constitutive relation model for the concrete, and a total of five concrete strength parameters were needed to define the failure surface of concrete (Willam-Warnke model), within which the uniaxial ultimate concrete tensile strength $\left(f_{t}\right)$ and the uniaxial ultimate concrete compressive strength $\left(f_{c}\right)$ were the most important input parameters to define the cracking and crushing pattern in concrete. The shear transfer coefficients $\left(\beta_{t}\right.$ and $\beta_{c}$ ) were also defined in the concrete material model to specify the shear strength reduction factor across the crack face. The concrete material is modeled considering a concrete compressive strength of $36.2 \mathrm{~N} / \mathrm{mm}^{2}$, a tensile strength of $2.8 \mathrm{~N} / \mathrm{mm}^{2}$ and an elastic modulus of $31.6 \mathrm{GPa}$.

To capture the full elastic-plastic behavior of the steel elements, their material nonlinearities were also considered and incorporated in the FE models. The steel beam, reinforcing bar and tie-bar were all modeled using the multi-linear kinematic hardening model with Von Mises yield criteria. The material nonlinearity was incorporated in the program by the multi-linear strain-stress curve. The material properties of different steel elements measured from the coupon tests and used in FE simulations are given in Table 1. 


\subsection{Contact modeling}

SCSFB are formed by embedding the steel beam within the concrete slab, and the composite action within the composite beam is achieved by the shear connection associated with the shear bond mechanism at the interface of steel and concrete. Therefore, the interaction mechanism between the two different materials was carefully defined in the FE models using contact elements at the interface between the steel beam and concrete slab. The surface-to-surface contact was used and for the particular case, it was considered as a rigid-to-flexible contact problem, where the steel section with higher stiffness was considered as the rigid element while the concrete with relatively low stiffness was considered as the flexible element. The steel beam surfaces in contact with the concrete slab was chosen as target surface and modeled using the TARGE170 element, while the flexible and deformable concrete element surfaces at the interface were set as the contact surface and modeled using the CONTA174 element. It was important to define correct contact modeling parameters, since the behavior of the contact model is greatly influenced by the set of several factors such as the initial contact conditions, the penetration tolerance, the contact stiffness, etc. The mesh generation in the FE model would cause some small initial penetrations, and in order to ensure the correct initial contact, all these initial penetrations were excluded in the contact model. It was modeled in such a way that the contact pairs would be only in contact in the initial geometry, i.e. the two contact elements would be "just in touch". The penetration tolerance is used in conjunction with the augmented Lagrangian method, which is the default contact algorithm for the surface-to-surface contact modeling. The contact stiffness defines the amount of penetrations between the two surfaces in contact. Based on the material properties of the deformable element, the ANSYS program can automatically estimate a default 
value for the contact stiffness. It should be addressed that higher contact stiffness value could lead to a decrease in the amount of penetration and convergence difficulties. If the contact stiffness factor is underestimated, global convergence difficulties might be caused by too much penetration rather than by residual forces. If it is overestimated, the global convergence might require many equilibrium iterations for achieving convergence tolerance rather than penetration.

The optimum inputs of the penetration tolerance FTOLN $=1.0$ and that of the contact stiffness FKN $=0.1$ were achieved during the FE calibrations, and a good comparison for the slips, deflections, ultimate loads and failure mechanisms between the FE analysis and test results were achieved.

\subsection{Boundary conditions and loadings}

To comply with the test specimen conditions, the FE models have two supports at $100 \mathrm{~mm}$ from either end. The boundary conditions of the beam supports were modeled on the bottom flange of the steel beam. At one support, translations in global directions $\mathrm{X}, \mathrm{Y}$ and $\mathrm{Z}$ were restrained, while at the other support, translations in global $\mathrm{Y}$ and $\mathrm{Z}$ directions would be restrained. Considering the symmetry of specimens, only a half of the beams were modeled in the FE analysis with appropriates boundary conditions applied to the symmetric plane. All the nodes on the cutting plane of the steel beam and concrete slab were restricted in the longitudinal $\mathrm{Z}$ direction to simulate the symmetry conditions.

The displacement loading control method was adopted in solution of the FE analysis, and the load (displacement) was applied on the top of the concrete slab. In order to distribute uniformly the loads over the slab width, and also avoid the stress concentration in concrete slab under the loading points, $40 \mathrm{~mm}$ thick steel plates were 
modeled to distribute the applied load. The displacement was incrementally applied to the FE model by dividing the total amount of load into a number of sub-steps. The automatic time stepping was enabled to permit bisection to allow recovery when the nonlinear response occurred and also if convergence failed. The Newton-Raphson equilibrium iteration was adopted to provide convergence at the end of each load increment within the tolerance limits.

\section{FE models calibration}

To verify and confirm the FE model formulation, one specimen was modeled using ribbed slab with $1.5 \mathrm{~mm}$ thick steel deck as that used for the test specimens (Fig. 6), and one specimen was modeled using a solid slab, and the two FE results were compared with the test results. The load vs. mid-span deflection curves of the computed models and the test specimen are shown in Fig. 7. It was remarked that the configuration of the concrete slab do not influence the load bearing behavior of the composite beam, however it would have a small penalty on the flexural stiffness. It was shown that the model with ribbed slab gives the load bearing capacity more close to the test result, while the deflections obtained from the model with solid slab were more close to the flexural bending test. However, it was observed that the difference between all these models was negligible, and modeling the specimens using solid slabs can accurately predict the structural behavior of the composite beam. It is observed that the computational curves generally agreed with the test results.

The model using the solid slab was then used in the finite element analysis of the four tested specimens, and the results were verified against the test results, in terms of the load vs. mid-span deflection, the characteristic loads (crack load, yield load and ultimate load) and slips as well as the failure modes of the beams. The graphical 
comparisons between the test and FE simulation results are shown in Fig. 8, and the characteristic values are given in Table 2 for comparison. It can be seen from the load-deflection plots that the FEA curves follow the experimental curves very closely. The ultimate loads predicted using FEA $\left(P_{\text {FEA }}\right)$ appear in good agreement with the experimental results $\left(P_{\mathrm{EXP}}\right)$. It can be remarked from Table 2 that the maximum differences between the numerical results $\left(P_{\mathrm{FEA}}\right)$ and the test results $\left(P_{\mathrm{EXP}}\right)$ are $2.5 \%$, $3.2 \%, 6.5 \%$ and $7.9 \%$ for SCCFB 1, SCCFB 2, SCCFB 3 and SCCFB 4, respectively. Generally, the results predicted by FEA are slightly higher than those obtained from the test program. The values of $P_{\mathrm{EXP}} / P_{\mathrm{FEA}}$ ratio $(R)$ are $0.98,0.97,0.93$ and 0.92 for SCCFB 1, SCCFB 2, SCCFB 3 and SCCFB 4, respectively.

The failure modes at the ultimate loads of the specimens were also compared. The test specimens were failed in plastic flexural with concrete crushing for SCCFB 1 and SCCFB 2 and in shear connection failure for SCCFB 3 and SCCFB 4. Good agreements were also achieved regarding the failures modes observed. In the FEA, the specimens SCCFB 1 and SCCFB 2 also failed by plastic flexural characterized by the concrete crushing on the top of concrete slab and also the yielding observed in the cellular steel beams. In specimens SCCFB 3 and SCCFB 4, the computations failed without that the concrete slab reached the specified concrete compressive strength. As for the experimental program, it was revealed that the tie-bar elements combined with the concrete to form the shear connections also yielded at the vicinity of the ultimate load, while the longitudinal reinforcing bars within the concrete slab did not yield at the end of the computations.

The calibrated results show excellent agreements between the test results and those obtained from FEA simulations, in terms of the ultimate load, slip, stress and failure modes. The comparison between the two engineering investigation methods leads to 
the conclusion that the developed FE models are reliable, sufficiently accurate, and can be used to predict the bearing strength as well as the failure mechanisms of the shallow cellular composite floor beams.

\section{Parametric study of shallow cellular composite floor beam}

In this section, a parametric study on concrete slab and steel beam is performed where the comparisons are based on specimen SCCFB 2. The terminology of the geometry of the structural steel section involved in the study is shown in Fig. 10.

\subsection{Influence of the effective width of the concrete slab}

In ordinary down-stand composite beam design, the effective width of concrete slab is usually taken equal to $1 / 4$ of the beam span. However, previous research [1] suggested that the effective width of the concrete slab should be taken equal to Span/8 when designing slim floor beams. The purpose was to avoid an overestimation of the longitudinal shear resistance and the degree of composite action within the composite beam. In the experiment program presented by Chen et al. [24], the effective width of the concrete slab was taken equal to Span/4 as suggested in international design codes Eurocode 4 (EN1994-1-1:2004) [26], British Standard (BS5950-3.1:1990) [7]). Another reason for adopting this recommended slab width was also to provide adequate anchorage for the reinforcing tie-bar element $(\varnothing 14 \mathrm{~mm})$ used for the shear connection.

To evaluate the influence of the effective width of the concrete slab on the overall behavior of SCCFB, the composite beam was modeled with the two different values suggested $(\operatorname{Span} / 4(1000 \mathrm{~mm})$ and $\mathrm{Span} / 8(500 \mathrm{~mm}))$. The material properties of concrete and steel were the same as those of specimen SCSFB 2. It was observed that, 
the increase in concrete slab width has moderate effects on the stiffness and strength of shallow cellular composite beam. Obviously, the bearing capacity and the flexural stiffness of the composite beam are all increased with the concrete slab width. Using Span/4 for the concrete slab width increased the bearing capacity of the composite beam by $5 \%$. Also, the maximum slip measured on model with $1000 \mathrm{~mm}$ slab width was reduced by $16 \%$ approximately. However, it was observed that the increase in concrete slab width did not increase the slip capacity of the composite beam, especially after the concrete cracking. Hence, the increase in concrete slab width had not considerably increase the composite action in the composite beam.

\subsection{Influence of concrete topping above the steel beam}

Shallow cellular composite floor beams can be constructed with or without concrete cover above the steel beam. However, it is obvious that this topping concrete could also enhance the composite action by increasing the shear bond contact between the steel beam and concrete slab. For this purpose, a minimum thickness of this concrete would be required to achieve the desired composite behavior. To assess the influence of the concrete topping on the load bearing capacity, as well as on the overall composite action and also determine a minimum thickness, the concrete cover $\left(D_{c}\right)$ was varied from 0 to $40 \mathrm{~mm}$ above the top flange of the steel beam, with an increment of 10mm. Similarly, same material properties as those for specimen SCCFB 2 were adopted in the numerical simulations. The obtained load versus mid-span deflection and load versus slip curves were compared in Figs. 11(a) and 11(b). The concrete topping above the steel beam is found having great influences on the flexural stiffness and load bearing behavior of the shallow cellular composite floor beam. Adding $40 \mathrm{~mm}$ thick of concrete above the steel beam increased the moment capacity of the 
beam by $16 \%$, while the maximum slip is reduced by $27 \%$. However, it is remarked that the use of concrete above the steel beam will also lead to a penalty of slight reduction in the ductility of the composite beam section. This investigation confirmed the fact that the concrete topping above the top flange of the steel beam is effective in improving the composite action and the longitudinal shear resistance of the shallow cellular composite beam. From the slips curves, it is observed that at certain range of concrete cover thickness, the influence on the slip capacity was not considerable. The reduction becomes more obvious for $30 \mathrm{~mm}$ and $40 \mathrm{~mm}$ concrete cover depth. The concrete topping provides an encasement for the steel beam, and therefore sufficient composite behavior within the beam section. Therefore, in order to achieve sufficient composite action and load bearing resistance, it is suggested that when concrete topping is provided above the steel beam, a minimum concrete topping depth of $30 \mathrm{~mm}$ should be provided with sufficient transverse reinforcement in form of mesh. This not only enhances the flexural behavior of slim composite floor beam, but also provides sufficient insulation for the composite floor in fire conditions.

\subsection{Effects of steel web thickness and bottom flange thickness}

The influences of the steel web and bottom flange thicknesses on the behavior of shallow cellular composite beams were investigated by varying the value of web thickness tw and bottom flange thickness tb. The steel thicknesses used for web post and bottom flange usually range from $8 \mathrm{~mm}$ to $20 \mathrm{~mm}$. Therefore, values of $10 \mathrm{~mm}$, $14 \mathrm{~mm}$ and $20 \mathrm{~mm}$ were adopted for the numerical investigations and the obtained results were compared in the moment versus mid-span deflection curves shown in Fig. 12 and Fig. 13. The cross-section of the steel beam is that of test specimen with $10 \mathrm{~mm}$ thick for the top flange, $14 \mathrm{~mm}$ thick for the bottom flange while the web post is 
varied for $10 \mathrm{~mm}, 14 \mathrm{~mm}$ and $20 \mathrm{~mm}$ when investigating the influence of the web thickness. In analyzing the influence of the bottom flange, the top flange and web post are all modeled in $10 \mathrm{~mm}$ thick, while the bottom flange thickness is varied for $10 \mathrm{~mm}$, $14 \mathrm{~mm}$ and $20 \mathrm{~mm}$. The $10 \mathrm{~mm}$ thick parts are supposed to have yield strength of 460 $\mathrm{MPa}$ as measured in test, while the $14 \mathrm{~mm}$ and $20 \mathrm{~mm}$ parts are modeled with $410 \mathrm{MPa}$ in yield strength.

It is remarked that increase in the steel web post thickness has little effects on the stiffness and strength of the composite beam. This phenomenon can be explained by the fact that the buckling effect that could affect the steel web is not in concern for shallow cellular composite beam, since the steel beam is highly encased within the concrete slab. The steel beams are encased in the concrete slab and the openings are filled with concrete and tie-bar elements and thus it increases the vertical and longitudinal shear capacities of the composites beams and free from the buckling and Vierendeel bending. In contrast, the effect of increasing the bottom flange thickness is more significant, since the bottom flange significantly contributes to the overall stability of the composite floor. Globally, it is observed that increasing the web thickness by $10 \mathrm{~mm}$, the load bearing capacity of the composite beam is increased by $4 \%$, while increasing $10 \mathrm{~mm}$ in the bottom flange thickness can lead to an increase of $28 \%$ in load bearing capacity of the composite beam. As depicted in Figs. 12 and 13, it is clear that increasing the capacity of the steel web slightly affects the flexural stiffness of the composite beam, while increasing the capacity of the bottom flange greatly enhance both the strength and stiffness of the composite beam. It is also demonstrated that the ultimate strength of a composite slim floor beam can be substantially increased by choosing steel sections with high strength in bottom flange rather than those with high steel web strength. 


\subsection{Effects of steel web opening size}

The influence of the opening size (opening diameter $D$ ) on the overall behavior of the shallow cellular composite beam was also investigated, by varying the opening diameters for $50 \mathrm{~mm}, 100 \mathrm{~mm}$ and $140 \mathrm{~mm}$. These openings are defined as "moderately perforated", "normally perforated" and "highly perforated", respectively.

In this study, the same sectional geometry and material properties as those of specimen SCCFB 2 were adopted, except the opening size. Figs 14(a) and 14(b) illustrate the influence of web perforation on the load bearing capacity and on the slip capacity of the shallow cellular composite beam, respectively. The behavior of the composite beam is influenced by the opening size. The load bearing capacity of the composite beam was found decreasing with the increase of the opening diameter. The ductility of the composite beam was also found influenced by the steel web perforation, which would decrease when the steel beam is highly perforated. The slip stiffness also increased with the web opening diameter. But the increase in the slip stiffness was not proportional to the increase of the opening diameter. An optimum web opening size should be satisfied to enable an effective composite performance and an effective load capacity. From the numerical simulations, it is suggested that steel web opening sizes more than $75 \%$ of the steel web depth are note suggested in designing shallow cellular composite floor beam.

\subsection{Effects of web opening spacing}

The effect of web opening spacing was investigated in term of the web post length $(w)$ between two consecutive openings. The web post length $(w)$ was varied from $10 \mathrm{~mm}$, $50 \mathrm{~mm}, 100 \mathrm{~mm}$ and $200 \mathrm{~mm}$, representing tw, $5 t_{w}, 10 t_{w}$ and $20 t_{w}$, respectively. The finite element models have $100 \mathrm{~mm}$ opening diameter and have variable only in 
opening spacing. The others parameters were the same as those used for the calibration of specimen SCCFB 2. The load-deflection and load-slip curves for models with 10, 50, 100 and 200mm web post lengths are illustrated in Figs. 15(a) and $15(\mathrm{~b})$, respectively. It is found that the load bearing capacity of the composite beam was not proportional to the web opening spacing. The loading capacity of the composite beam was reduced for small and large spacing values that are $10 \mathrm{~mm}$ and $200 \mathrm{~mm}$. But the flexural stiffness of the composite beam was not influenced by the web opening spacing. The strength reduction for the beam with $10 \mathrm{~mm}$ web post length is likely due to the stress concentration around the openings and the web post. The load-slip curves illustrate a phenomenon contrary to that observed in the load bearing behavior. The slip stiffness appeared significantly influenced by the shear connection spacing, as the slip decreased with the shear connection spacing decrease. Therefore, from the parametric study, it is suggest that in the design of shallow cellular composite floor beams, very close opening layout should be avoided.

\section{Discussions and design considerations}

From the tests, it was shown that one of the critical failure modes in specimens SCCFB 3 and SCCFB 4 was shear connection failure, or the failure of the infill concrete passing through the web openings. The findings derived from the FE simulations show that the shallow cellular composite floor beam could also fail in the steel beam section, under an excessive longitudinal shear force. Accordingly, the stress within the steel beam can be divided into two main parts: the stress caused by the composite action within the opening from the longitudinal shear forces and the stress caused by the bending moment and axial force as illustrated in Fig. 16. For the

local composite action, the steel web post serves to transfer the longitudinal shear 
force into the infill concrete, which leads to significant stress within the steel beam section. This shear force transfer mechanism usually results in a distinctive stress concentration around the web opening. Also, global force resulting from bending and axial force are all redirected to the steel web post, also leading to the concentration of stress within the steel web post. Failure in steel web post would occur when the steel section is designed with low yielding strength and/or with relatively thin web post compositely with considerably high strength concrete element.

Upon this analysis, the following geometrical requirements are proposed for design of a shallow cellular composite floor beam:

(1) In a cellular steel beam design, depth of the opening $\left(h_{D}\right)($ Fig. 10) and spacing between the adjacent openings $(S)$ should satisfy the follows condition:

$$
h_{D}=0.6 S
$$

(2) The length (w) (Fig. 10) between two adjacent web openings should satisfy the followings condition:

$$
w \geq 0.5 h_{D}
$$

(3) The depth of the steel web base $\left(S_{C b}\right)$ (Fig. 10) should not be less than $20 \mathrm{~mm}$ or less than two times the steel web thickness $\left(S_{C b} \geq 2 t_{w}\right)$.

\section{Conclusion}

A finite element analysis study of the structural behavior of shallow cellular composite floor beam was presented. The FE models were developed based on the flexural bending test specimens and including nonlinear contact modeling considering the adhesion, the friction and the local compression at the contact interfaces between the concrete slab and steel beam. The FE models were calibrated and validated against 
the test results, and were then used to perform intensive parametric studies. The following conclusions are drawn:

(1) Variation in the effective width of the concrete slab has moderate effect on the stiffness and strength of the composite girder. Using Span/4 for the concrete slab width instead of Span/8 increased the bearing capacity of the beam by only $5 \%$. However, it was observed that the increase in concrete slab width did not increase the slip capacity within the elastic stage, especially after the concrete cracking. Hence, the increase in concrete slab width had not considerably increase the degree of composite action of the composite beam.

(2) The concrete topping above the steel beam has a great influence on the performance of SCCFB such as the flexural stiffness and the load bearing capacity as well as the composite action and the longitudinal shear resistance. Adding $40 \mathrm{~mm}$ thick of concrete above the steel beam can increase the moment capacity of the beam by $16 \%$, while the maximum slip is reduced by $27 \%$.

(3) The variation in the bottom flange thickness mostly affects the flexural behavior of shallow cellular composite floor beam, rather than the web post. Increasing the web thickness by $10 \mathrm{~mm}$, the load bearing capacity of the composite beam was increased by only $4 \%$, while the increase of $10 \mathrm{~mm}$ in the bottom flange thickness can lead to an increase of $28 \%$ in load bearing capacity. Increasing the capacity of the bottom flange greatly enhance both the strength and stiffness of the composite girder.

(4) The structural behavior of the shallow cellular composite beam is influenced by the web opening size. The load bearing capacity of the composite beam decreases with increase of opening size. The ductility is also influenced by the steel web perforation, and it decreases when the steel beam is highly perforated. It is 
concluded that opening sizes more than $75 \%$ of the steel web depth are not suggested in design of a shallow cellular composite floor beam.

\section{Acknowledgments}

The authors appreciate greatly the National Science Foundation of the People's Republic of China for the support for this research under the Grant No.51078290. The funding, cooperation and assistance of many people from the organization are greatly acknowledged.

\section{References}

[1] Lawson RM, Mullett DL, Rackham JW. Design of asymmetric Slimflor beams using deep composite decking. The Steel Construction Institute, SCI Publication P1751859420443; 1997312

[2] Lawson RM, Bode H, Brekelmans JWPM, Wright PJ, Mullett DL. 'Slimflor' and 'Slimdek' construction: European developments. J Struct Eng00392553 1999; 77(8): 22 30.

[3] Lawson RM, Lim J, Hicks SJ, Simms WI. Design of composite asymmetric cellular beams and beams with large web openings. J Constr Steel Res0143974X 2006; 62(6):614-29.

[4] Hicks S. Current trend in modern floor construction. Mag Br Constr Steelwork Assoc (BCSA) 2003; 11(1): 32-3.

[5] Bernuzzi C, Gadotti F, Zandonini R. Semi-continuity in slim floor steel concrete composite systems. Proceedings of the 1995 1st European conference on steel structures, EUROSTEEL'95; 1995.

[6] Mullett DL. Slim floor design and construction. The Steel Construction Institute, SCI, Publication P110; 1992. 
[7] British Standard, BS5950-3.1. Structural use of steel work in building, part 3: design in composite construction, section 3.1 code of practice for design of simple and continuous composite beams; 1990.

[8] Mullett DL, Lawson RM. Slim floor construction using deep decking. The Steel Construction Institute, SCI, Publication P127; 1993

[9] Mullett DL. Composite floor system. Blackwell Science Ltd 0632041439; 1998.

[10] Wang Y, Yang L, Shi Y, Zhang R. Loading capacity of composite slim frame beams. J Constr Steel Res0143974X 2009; 65:650-61.

[11] Hegger J, Roggendorf T, Kerkeni N. Shear capacity of prestressed hollow core slabs in slim floor constructions. Eng Struct 2009; 31:551-9.

[12] Ranzi G, BradfordMA, Uy B. A direct stiffness analysis of a composite beamwith partial interaction. Int J Numer Methods Eng 2004; 657-72.

[13] Ranzi G. Short- and long-term analyses of composite beams with partial interaction stiffened by a longitudinal plate. Steel Compos Struct 2006; 6(3):237-55.

[14] Ranzi G. Locking problems in the partial interaction analysis of multi-layered composite beams. Eng Struct 2008; 30:2900-11.

[15] Karama M, Afaq KS, Mistou S. Mechanical behaviour of laminated composite beam by the new multi-layered laminated composite structures model with transverse shear stress continuity. Int J Solids Struct 2003; 40:1525-46.

[16] Uy BB, Bradford MA. Ductility of profiled composite beams. Part II: analytical study. J Struct Eng 1995; 121:883-9.

[17] Limazie T. and Chen S.M. Numerical procedure for nonlinear behavior analysis of composite slim floor beams. Journal of Constructional Steel Research, 2015; 106, 209219

[18] Daniels BJ, Crisinel M. Composite slab behavior and strength analysis. Part I: calculation procedure. Journal of Structural Engineering, ASCE 1993; 119(1):16-35. 
[19] Veljkovic M. Behavior and resistance of composite slabs, PhD Thesis, Lulea University of Technology, Lulea, Sweden, 1996.

[20] Abdullah R, Easterling WS. Determination of composite slab strength using a new elemental testmethod. Journal of Structural Engineering, ASCE 2007; 133(9):1268-77

[21] Widjaja BR. Analysis and design of steel deck-concrete composite slabs, PhD Thesis, USA: Virginia Polytechnic Institute and State University, 1997.

[22] Ferrer M, Marimon F. FEM modelling of composite slabs' shear connection and new friction system based on steel sheet punching, steel concrete composite and hybrid structures. In: Lam Dennis, editor. Proceeding of the 9th International Conference on Steel Concrete Composite and Hybrid Structures. Research Publishing Services; 2009.

[23] Tsalkatidis T, Avdelas A. The unilateral contact problem in composite slabs: experimental study and numerical treatment. Journal of Constructional Steel Research 2010; 66(3):480-6.

[24] Chen, S.M., Limazie, T. and Tan, J.Y. Flexural behavior of shallow cellular composite floor beams with innovative shear connections. Journal of Constructional Steel Research 2015; 106: 329-346.

[25] GB50010-2010 "China National Standard: Code for Design of Concrete Structures". China Building Industry Press, Beijing, 2010

[26] ENV1994-1-1. "Design of Composite steel and concrete structures, Part 1-1: General Rules and Rules for Buildings". Eurocode 4, 2004 


\section{Table captions:}

Table 1: Material properties of steel elements

Table 2: Comparison between experimental and finite element analysis results 
Tables:

Table 1: Material properties of steel elements

\begin{tabular}{lccc}
\hline Elements & Mean $f_{y}(\mathrm{MPa})$ & Mean $f_{u}(\mathrm{MPa})$ & $E_{s}(\mathrm{GPa})$ \\
\hline Top flange & 461.03 & 554.48 & 185 \\
Web post & 464.76 & 562.93 & 185 \\
Bottom flange & 410.50 & 553.87 & 188 \\
Tie-bar $(\varnothing 14)$ & 548.3 & 586.70 & 206 \\
Long. bar $(\varnothing 10)$ & 415.0 & 588.30 & 210 \\
Trans. bar $(\varnothing 8)$ & 428.3 & 551.70 & 205 \\
\hline
\end{tabular}

$f_{y}-$ yield strength; $f_{u}-$ ultimate strength; $E_{s}-$ elastic modulus 


\section{Tables:}

Table 2: Comparison between experimental and finite element analysis results

\begin{tabular}{|c|c|c|c|c|c|c|c|c|c|c|}
\hline \multirow{3}{*}{ Specimen } & \multicolumn{7}{|c|}{ Characteristic loads $(\mathrm{kN})$} & \multicolumn{3}{|c|}{ Slips (mm) } \\
\hline & \multicolumn{3}{|c|}{ Exp } & \multicolumn{3}{|c|}{ FEA } & \multirow{2}{*}{$\mathrm{R}\left(P_{u}\right)$} & Exp & FEA & \multirow{2}{*}{$\mathrm{R}$} \\
\hline & $P_{c r}$ & $P_{y}$ & $P_{u}$ & $P_{c r}$ & $P_{y}$ & $P_{u}$ & & & & \\
\hline SCCFB 1 & 70 & 250 & 349.0 & 46.5 & 254.2 & 358.2 & 0.97 & 0.13 & 0.25 & 0.52 \\
\hline SCCFB 2 & 60 & 190 & 264.7 & 39.6 & 200.3 & 273.3 & 0.97 & 0.30 & 0.41 & 0.75 \\
\hline SCCFB 3 & 40 & 160 & 255.1 & 31.3 & 191.6 & 272.8 & 0.94 & 9.3 & 8.45 & 1.1 \\
\hline SCCFB 4 & 30 & 110 & 154.4 & 20.9 & 126.4 & 167.6 & 0.92 & 16.1 & 13.4 & 1.2 \\
\hline Average & & & & & & & 0.95 & & & 0.89 \\
\hline
\end{tabular}

$P_{c r}$ : Cracking load; $P_{y}$ : Yielding load; $P_{u}$ : Ultimate load of the composite beam; smax: Maximum slip at the end of the test; $R$ : Ratio (Exp/FEA); Exp: experimental result; FEA: finite element analysis result. 


\section{Figure captions:}

Figure 1: Ordinary Asymmetric Slim Floor Beam configuration

Figure 2: Typical arrangement of shear connection with circular opening in shallow cellular composite beam

Figure 3: Bending test and FE simulations specimens

Figure 4: Elements used for different element modeling

Figure 5: Meshed FE model of a typical SCCFB with "asymmetric I section" steel beam

Figure 6: FE model of SCCFB modeled with ribbed slab

Figure 7: Load vs. deflection comparison from test, solid slab and ribbed slab

Figure 8: Specimen's load versus mid-span deflections comparisons

Figure 9: Von Mises stress of concrete and steel beam at the ultimate loads

Figure 10: Terminology of the geometry of structural steel section

Figure 11: Influence of concrete toping above the steel beam on load and slip capacities

Figure 12: Effects of web thickness $\left(t_{w}\right)$

Figure 13: Effects of bottom flange thickness $\left(t_{b}\right)$

Figure 14: Influence of web opening diameter on the load and slip capacities

Figure 15: Influence of web opening spacing on the load and slip capacities

Figure 16: Different forces action inducing stress concentration in steel element with clothoidal opening shear connection 


\section{Figures:}

Figure 1

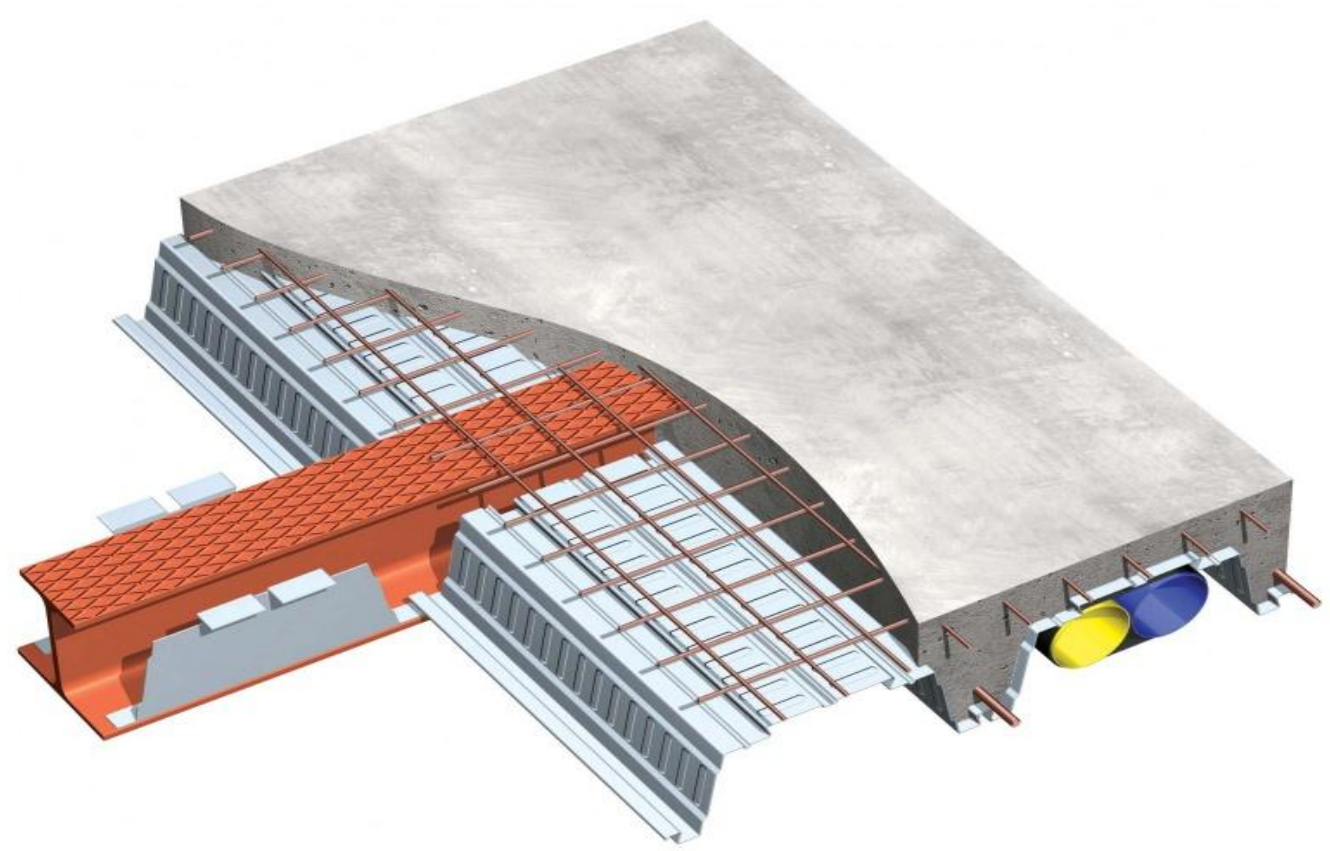

Fig. 1: Ordinary Asymmetric Slim Floor Beam configuration 
Figure 2

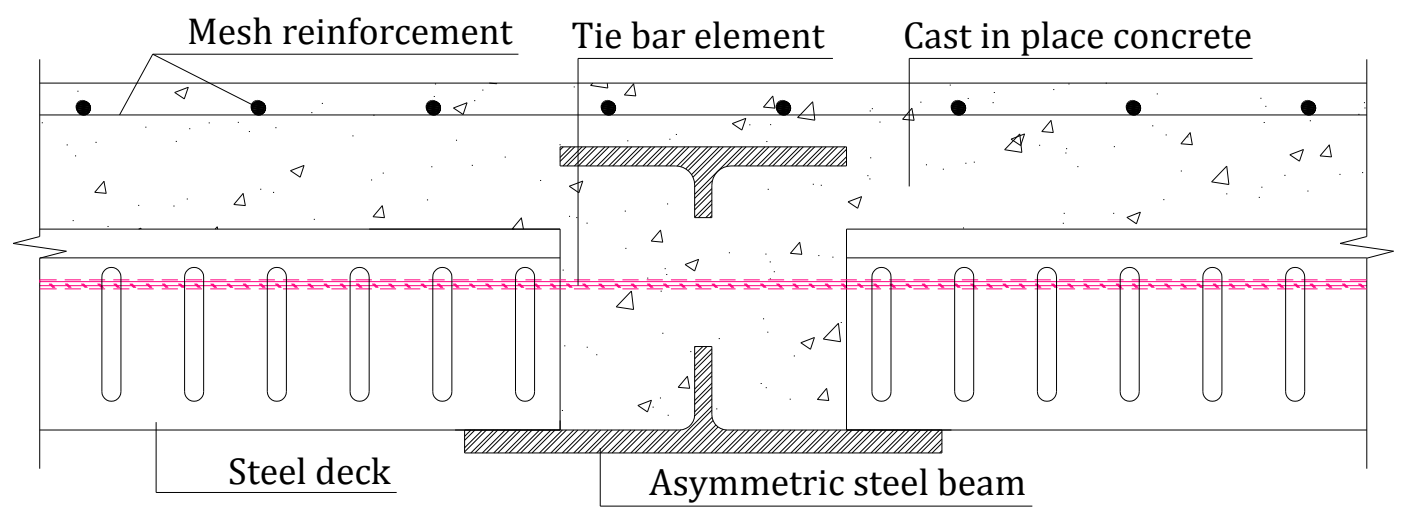

Fig. 2 Typical arrangement of shear connection with circular opening in shallow cellular composite beam 
Figure 3:
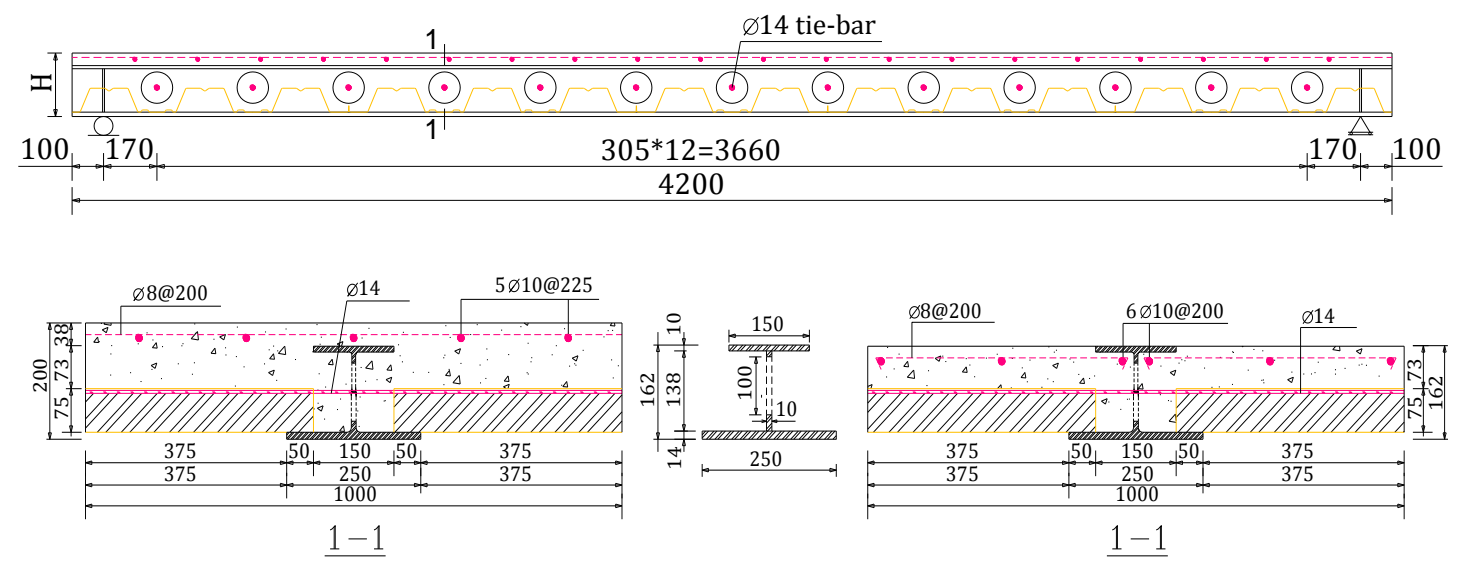

(a) Geometrical characteristics for specimens SCCFB 1 and SCCFB 2
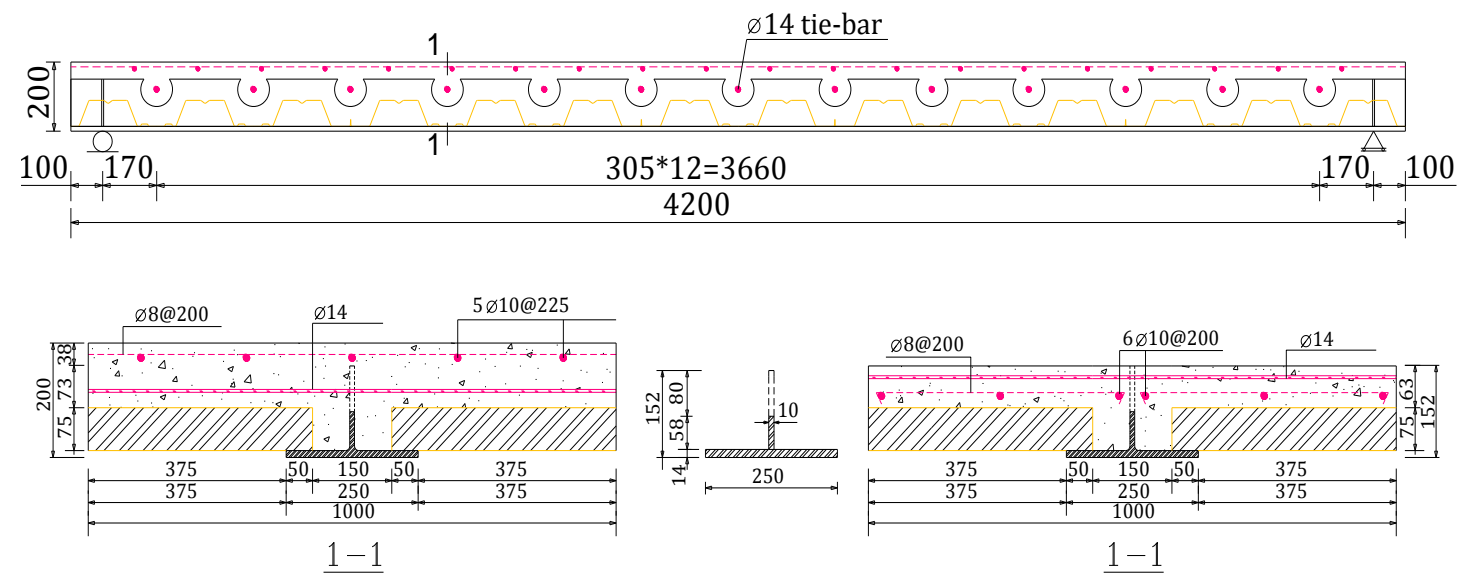

(b) Geometrical characteristics for specimens SCCFB 3 and SCCFB 4

Fig. 3: Bending test and FE simulations specimens 
Figure 4:
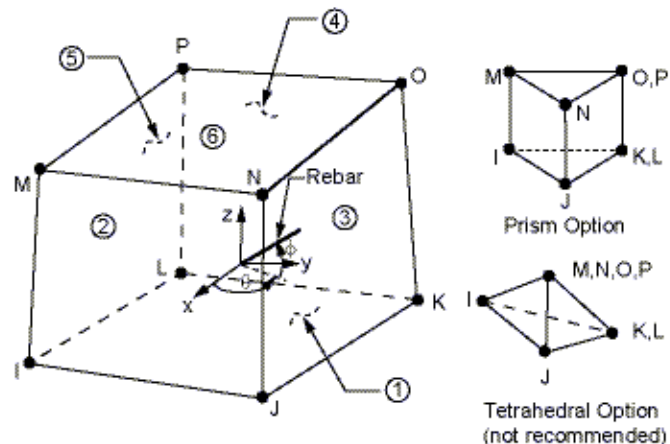

(a) Solid65 element for concrete

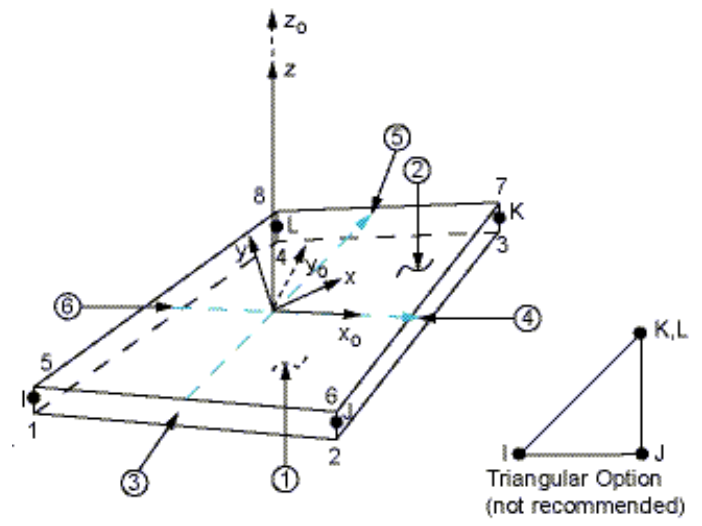

(b) Shell181 element for steel beam

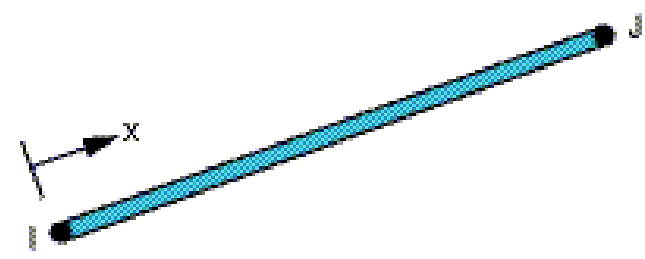

(c) Link8 element for reinforcements and tie-bars

Fig. 4: Elements used for different element modeling 
Figure 5
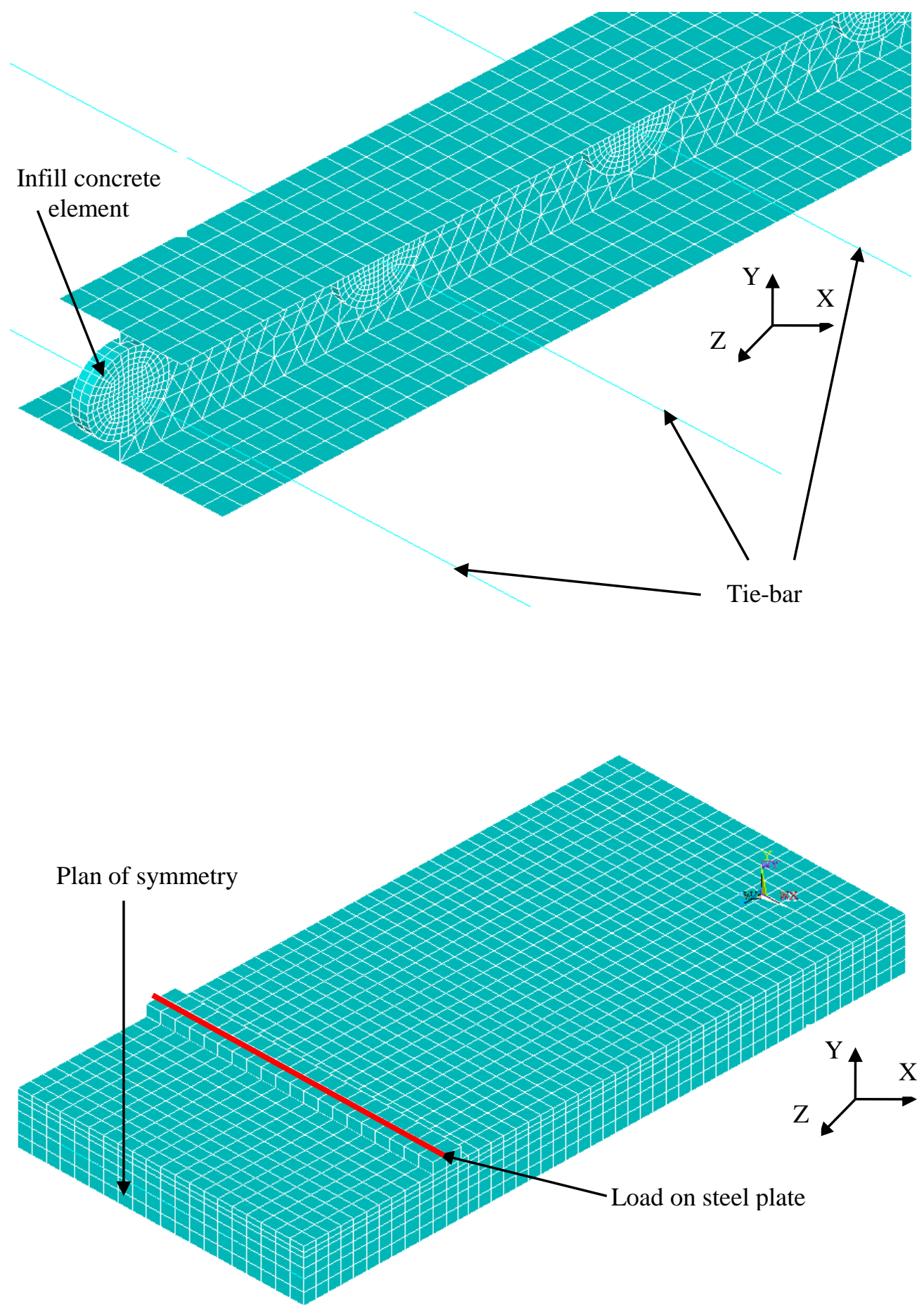

Fig. 5: Meshed FE model of a typical SCCFB with "asymmetric I section" steel beam 
Figure 6

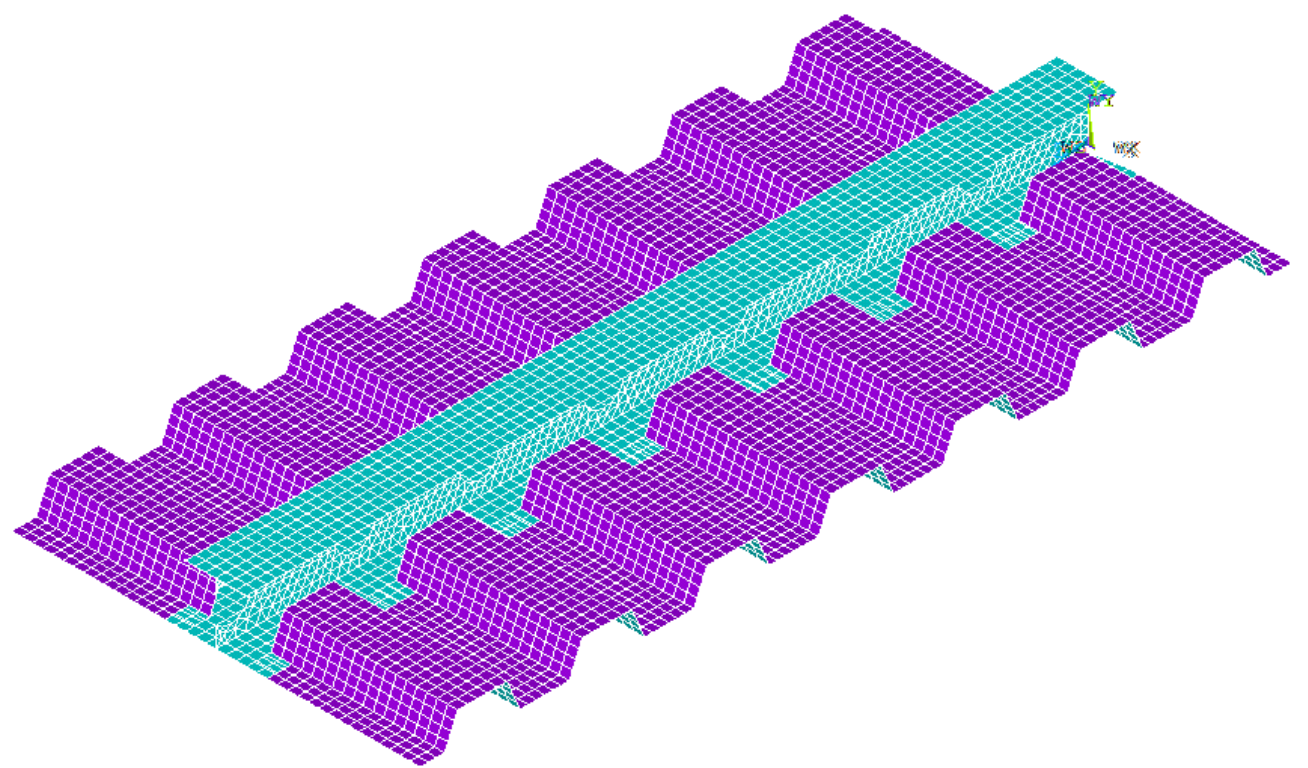

(a) Steel beam with profiled steel deck

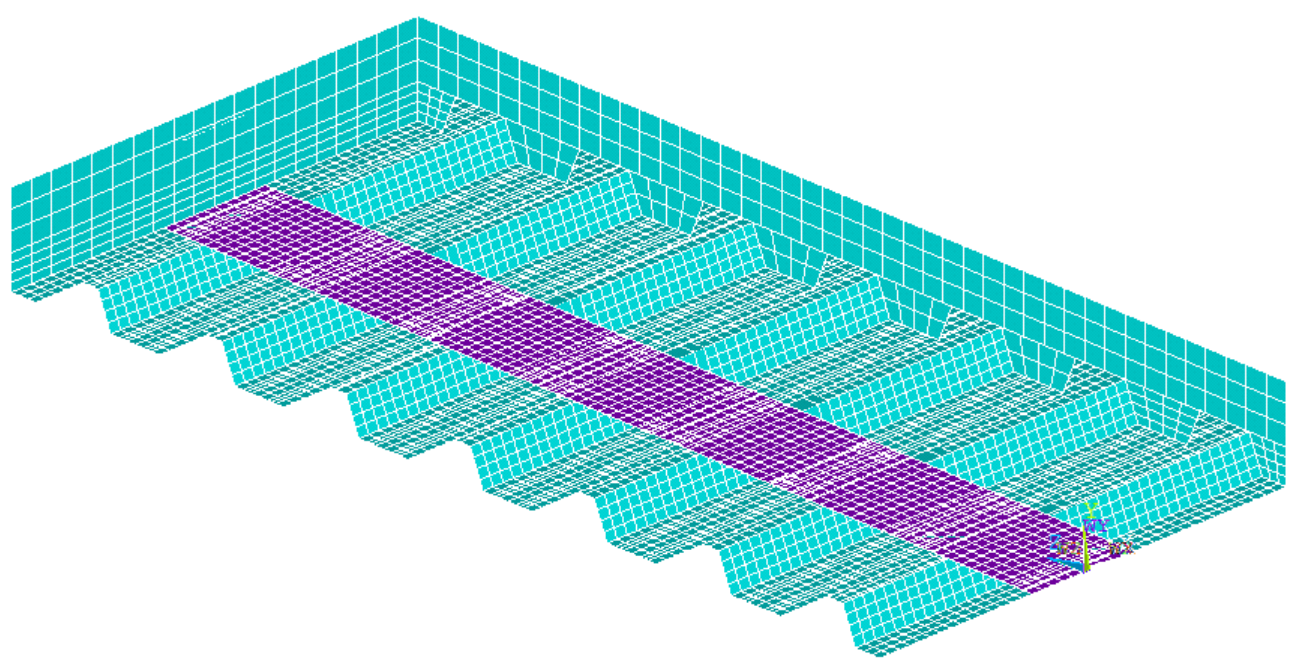

(b) Ribbed concrete slab

Fig. 6: FE model of SCCFB modeled with ribbed slab 
Figure 7

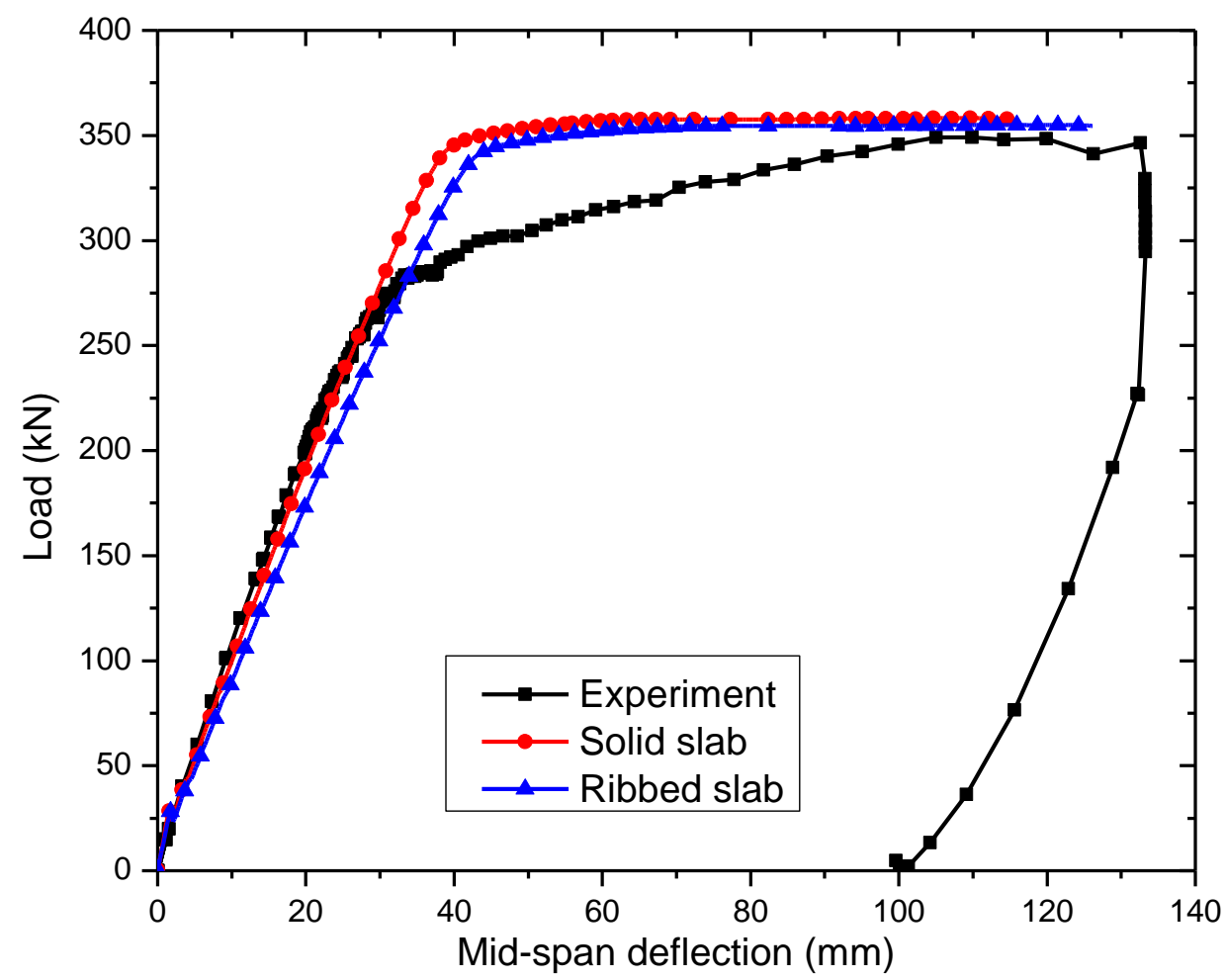

Fig. 7: Load vs. deflection comparison from test, solid slab and ribbed slab 
Figure 8

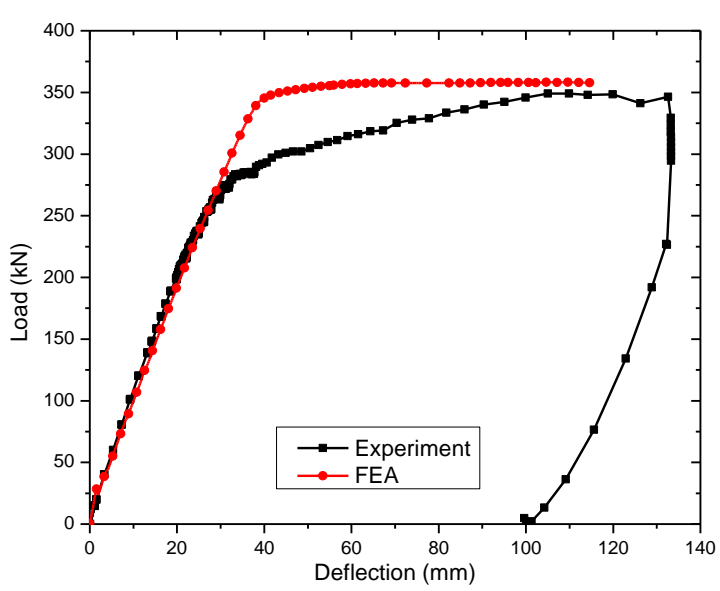

(a) Specimen SCCFB 1

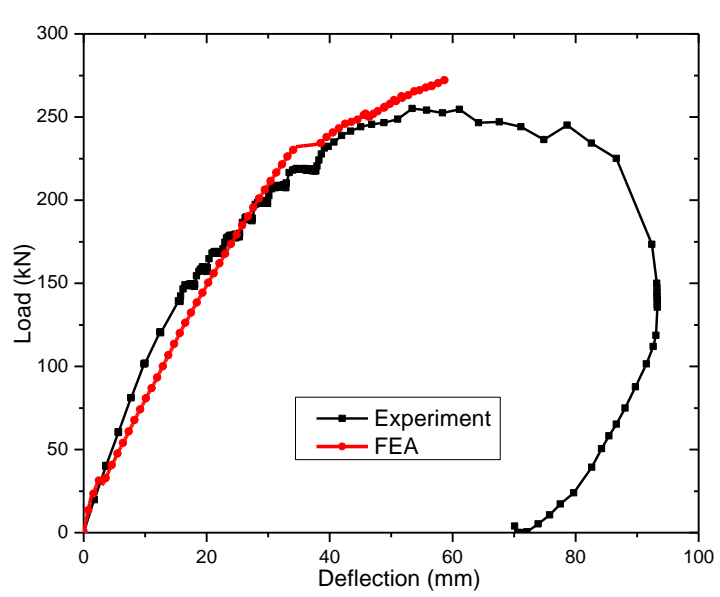

(c) Specimen SCCFB 3

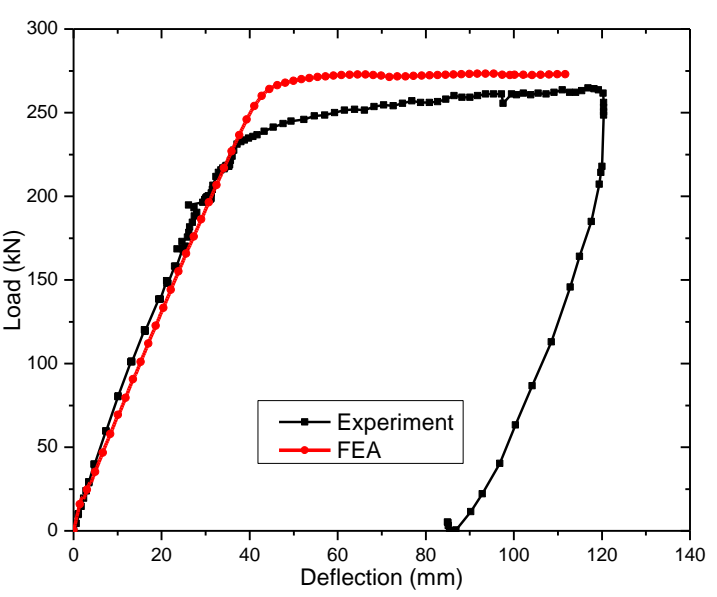

(b) Specimen SCCFB 2

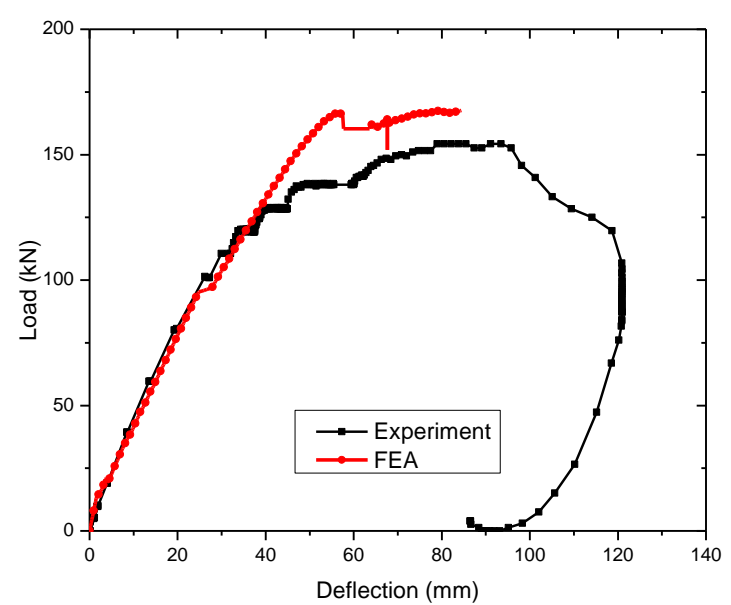

(d) Specimen SCCFB 4

Fig. 8: Specimen's load versus mid-span deflections comparisons 
Figure 9

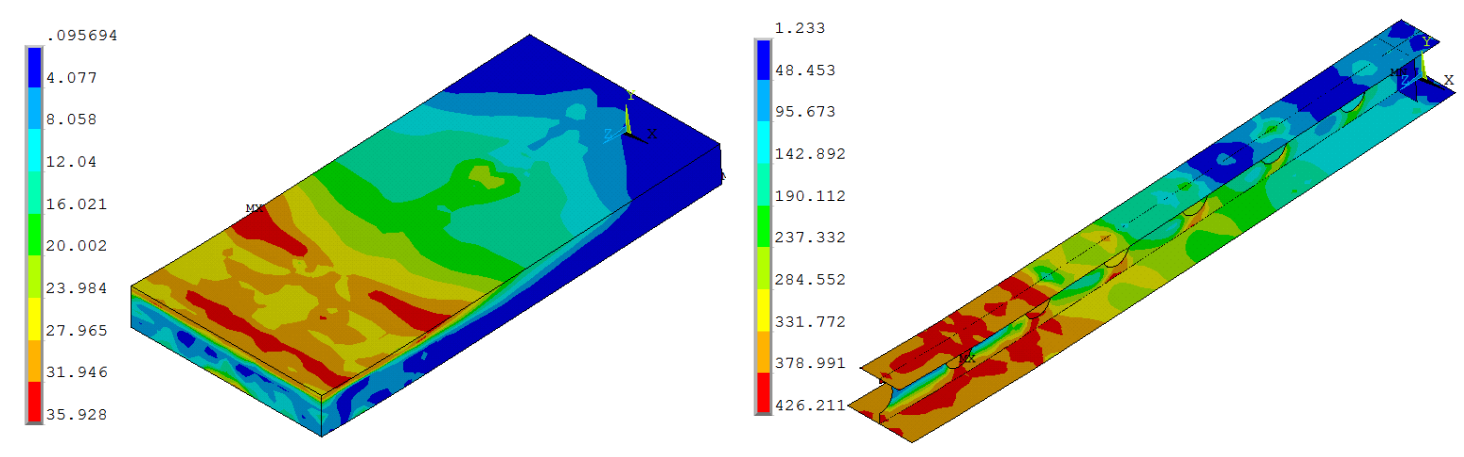

(a) Stress contour plot of concrete and steel beam in SCCFB 1

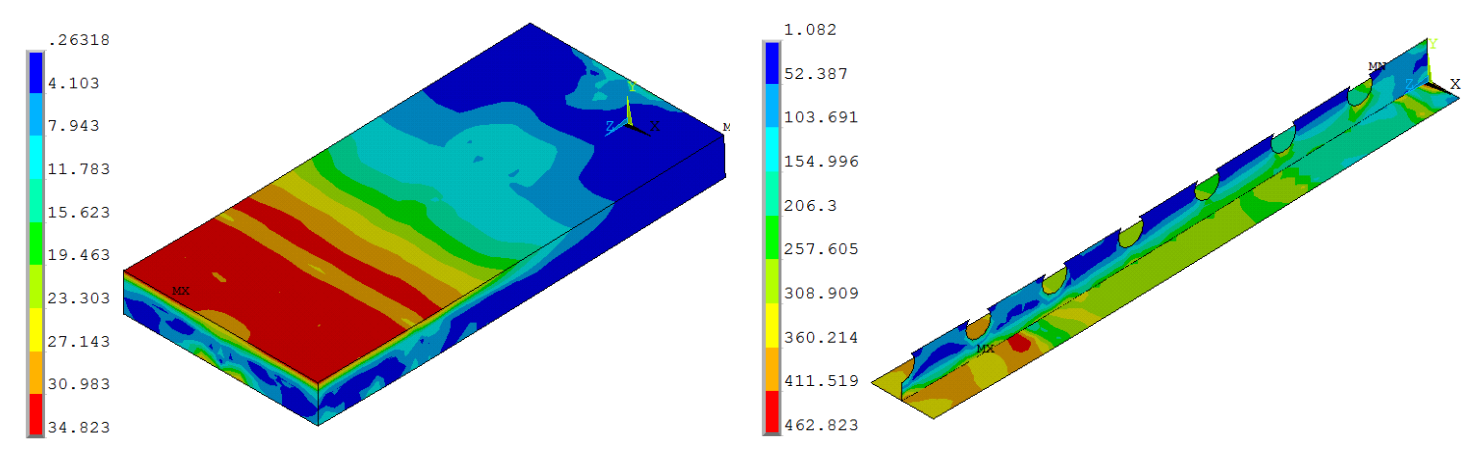

(b) Stress contour plot of concrete and steel beam in SCCFB 4

Fig. 9: Von Mises stress of concrete and steel beam at the ultimate loads 
Figure 10
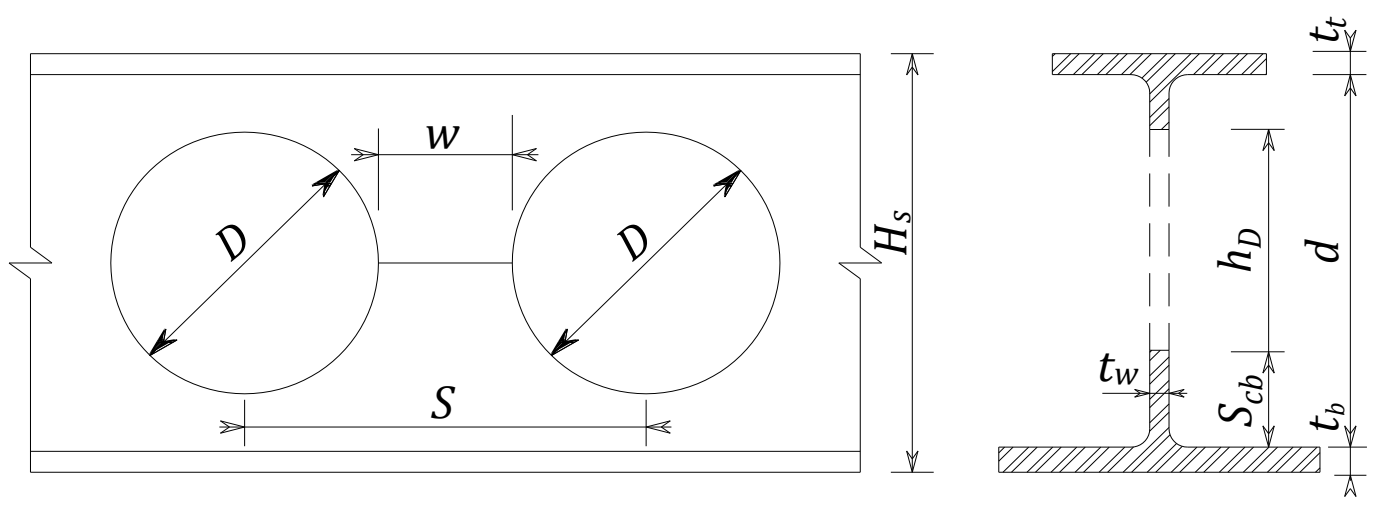

Fig. 10: Terminology of the geometry of structural steel section 
Figure 11

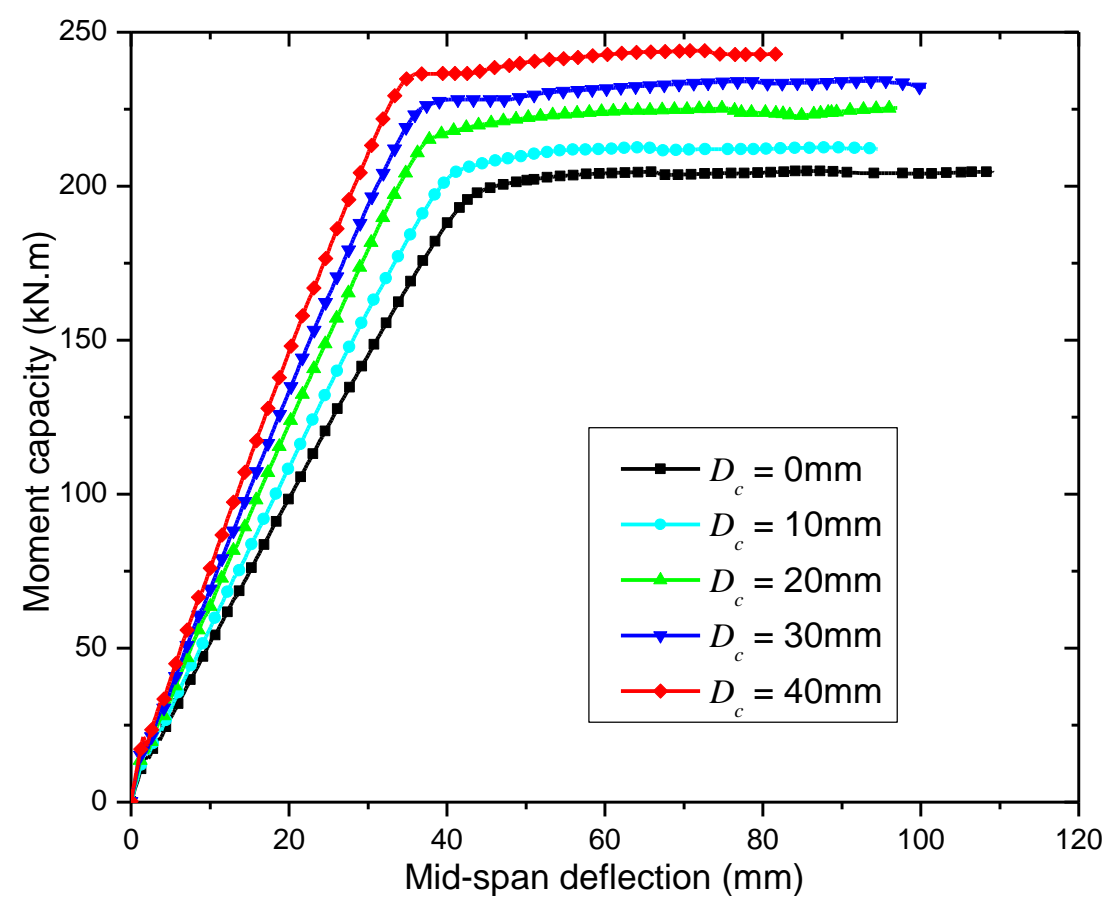

(a) Effect of concrete toping on the strength

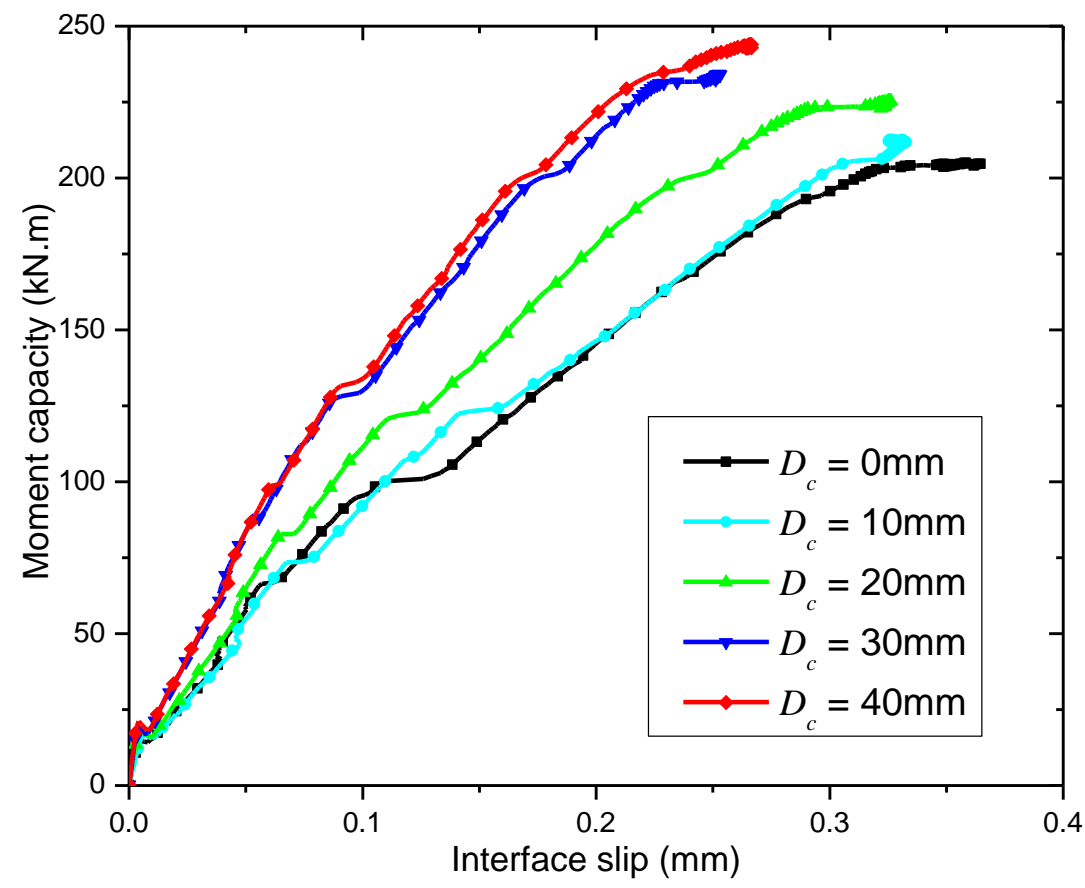

(b) Effect of concrete toping on slip

Fig. 11: Influence of concrete toping above the steel beam on load and slip capacities 
Figure 12

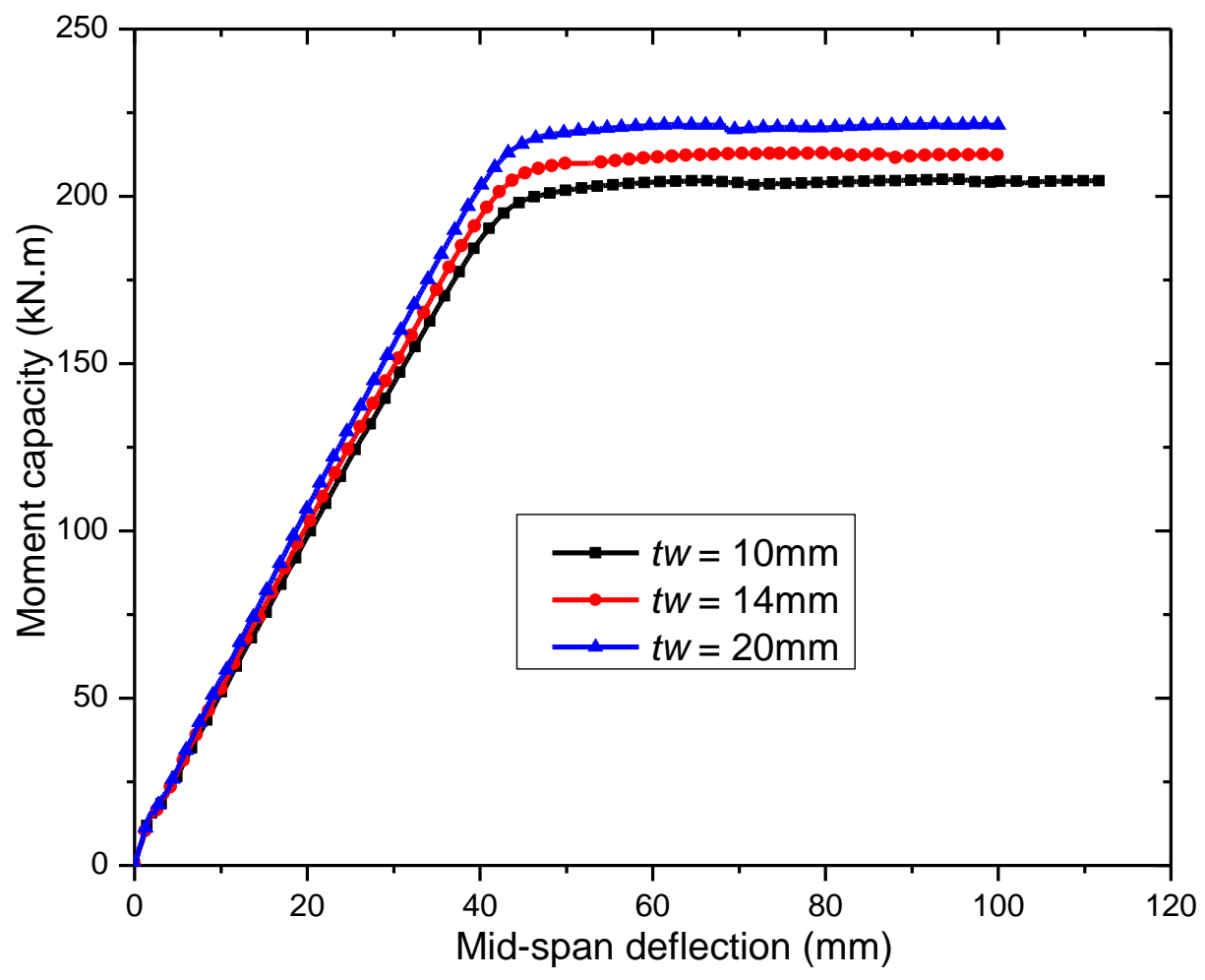

Fig. 12: Effects of web thickness $\left(t_{w}\right)$ 
Figure 13

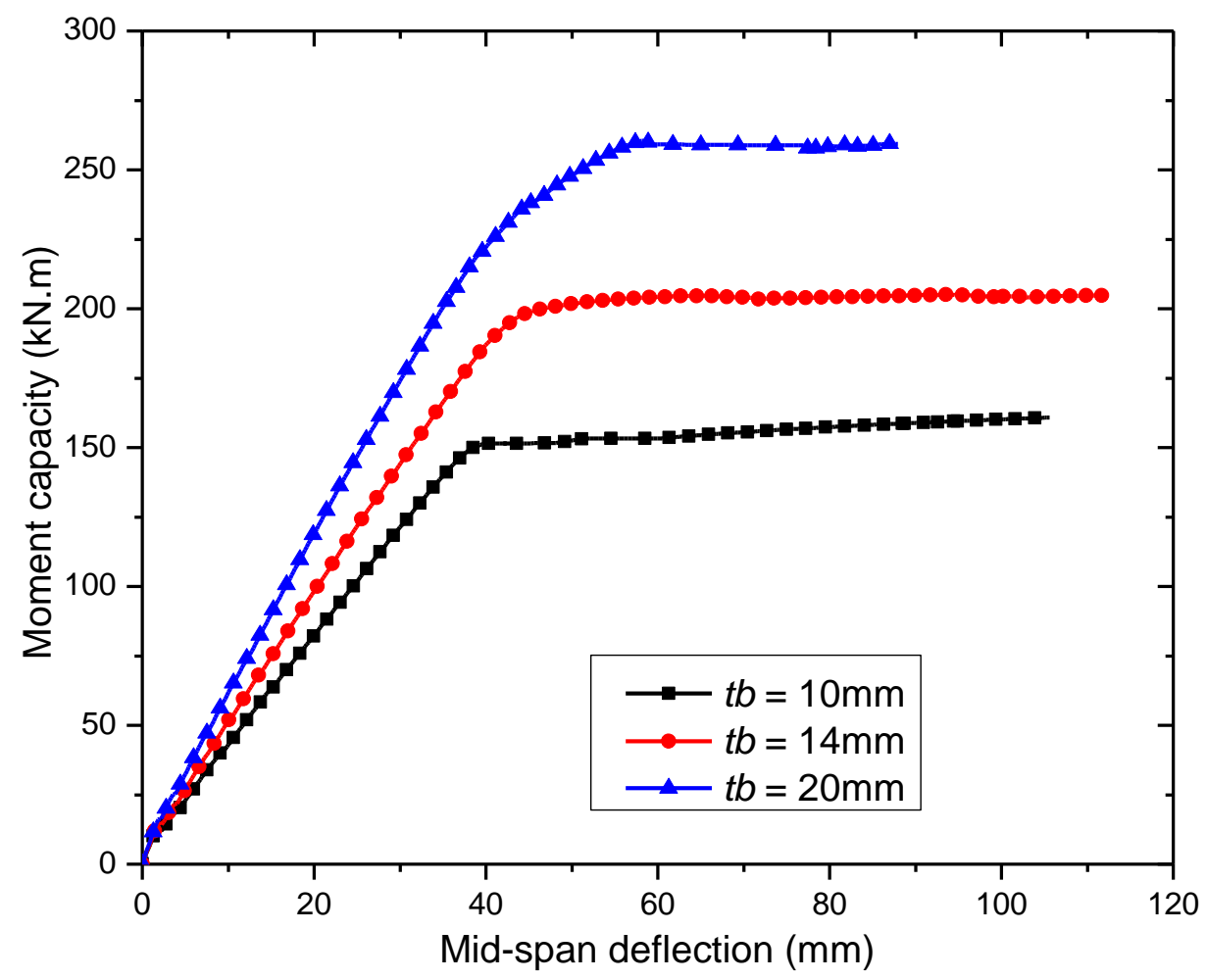

Fig. 13: Effects of bottom flange thickness $\left(t_{b}\right)$ 
Figure 14

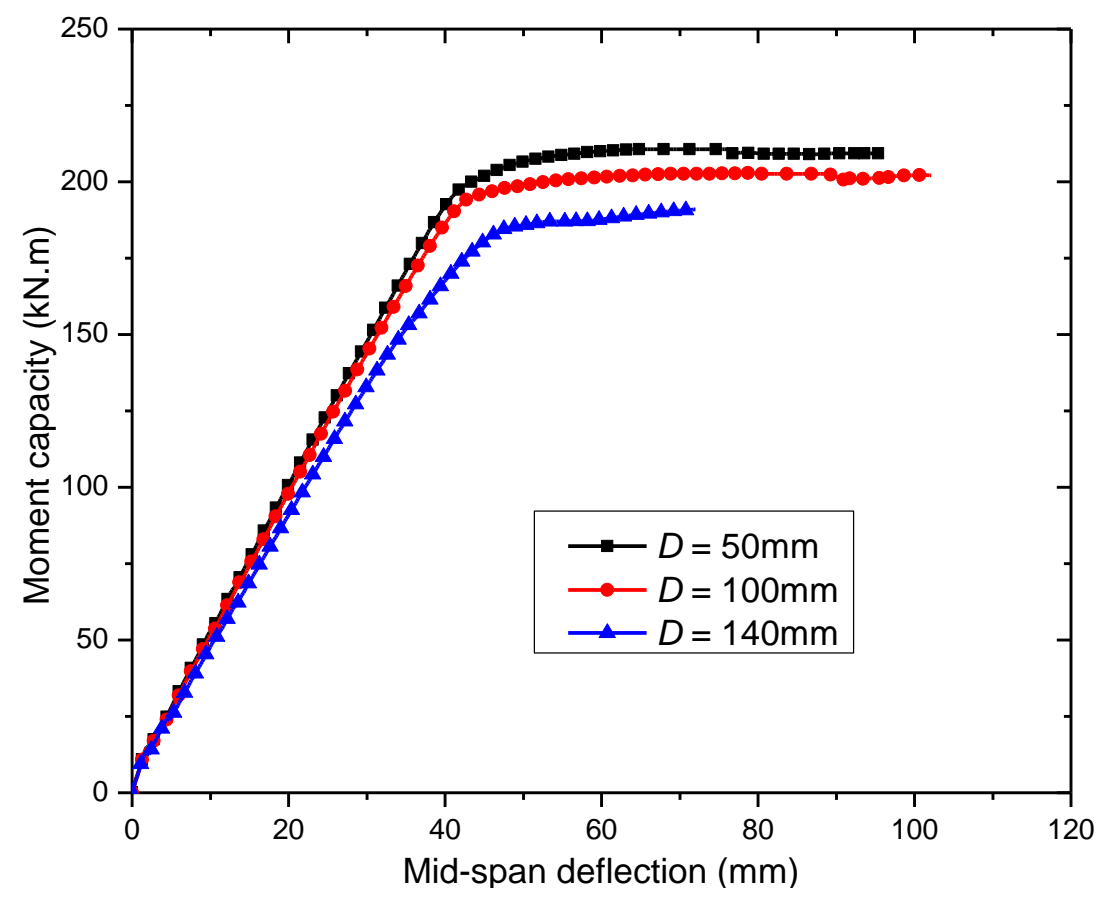

(a) Effect of opening size on the strength

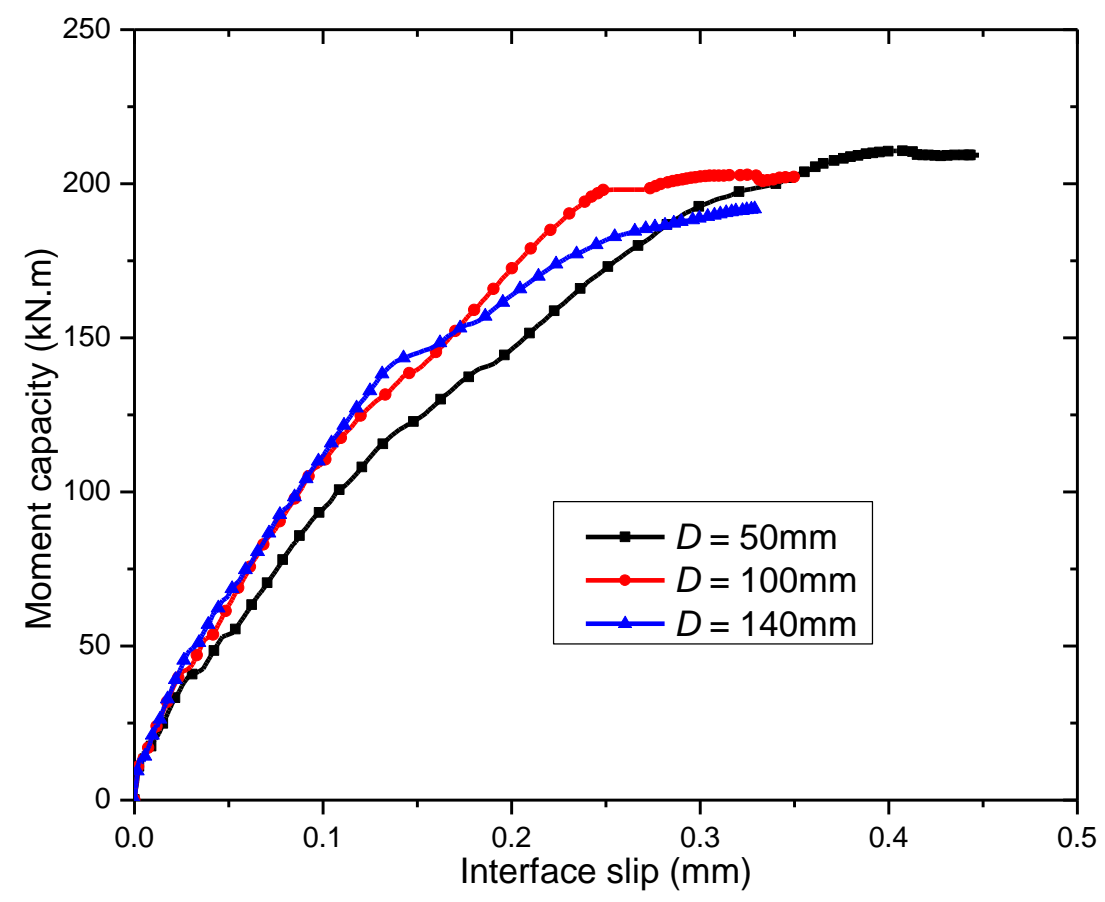

(b) Effect of opening size on slip

Fig. 14: Influence of web opening diameter on the load and slip capacities 
Figure 15

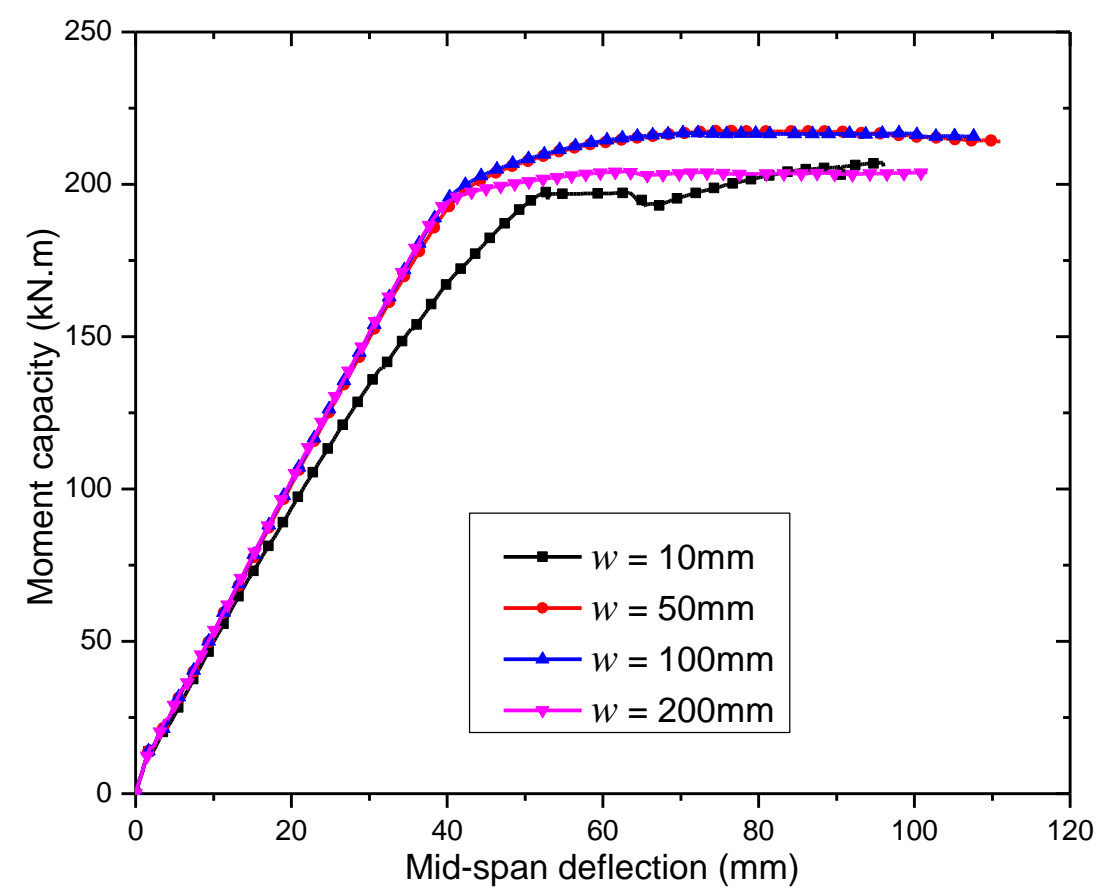

(a) Effect of opening spacing on the strength

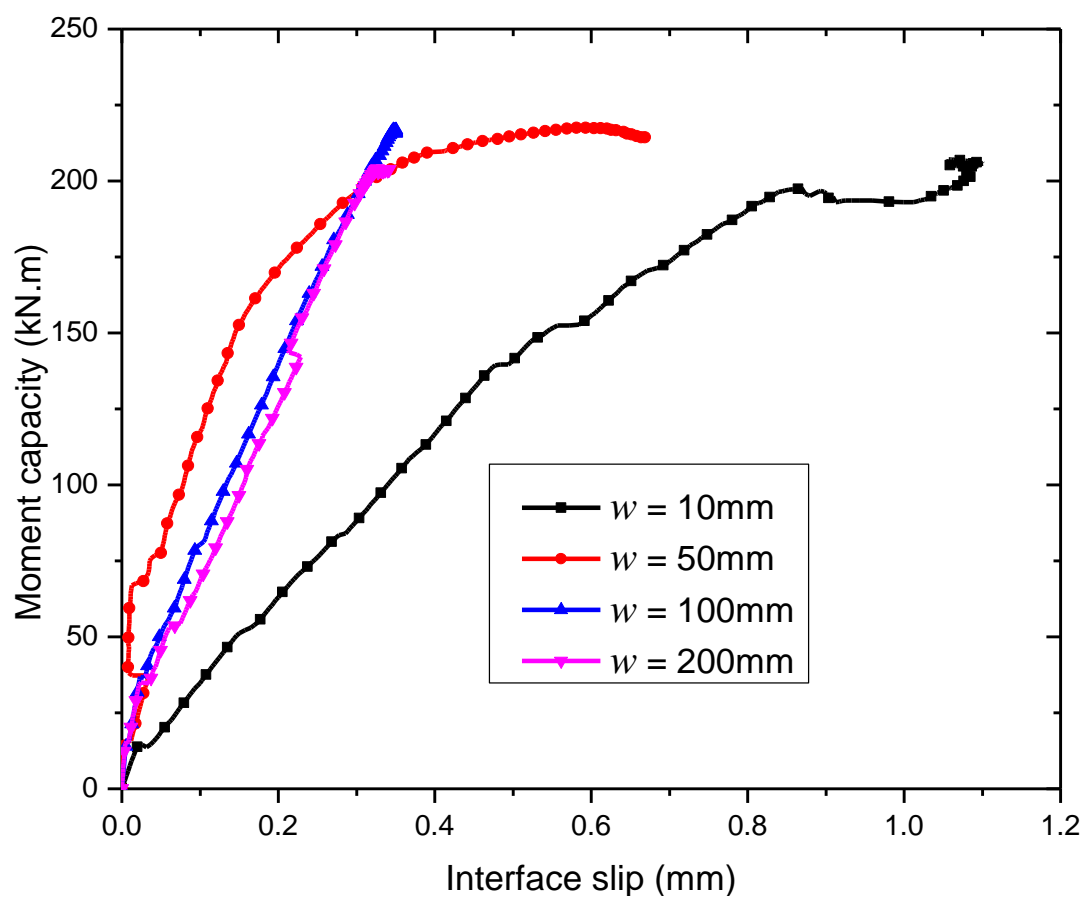

(b) Effect of opening spacing on slip

Fig. 15: Influence of web opening spacing on the load and slip capacities 
Figure 16

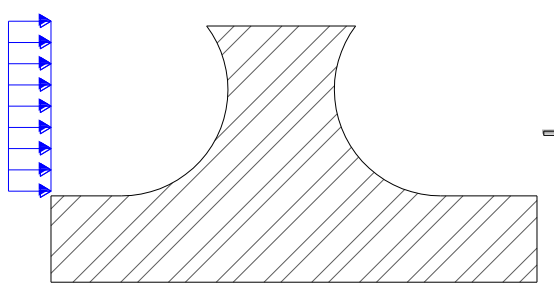

Local composite action

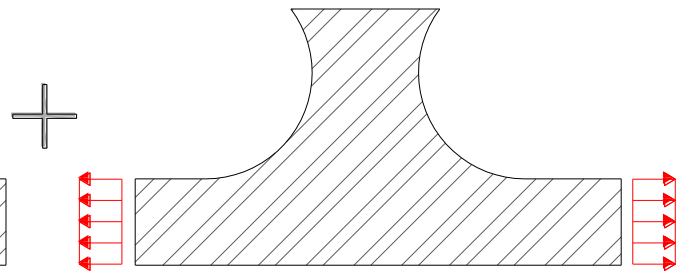

Bending and axial force actions

Fig. 16: Different forces action inducing stress concentration in steel element with clothoidal opening shear connection 